\title{
Estudo da associação entre antígenos de histocompatibilidade leucocitária e penfigoide bolhoso em pacientes brasileiros
}

Tese apresentada à Faculdade de Medicina da Universidade de São Paulo para obtenção do Título de Doutor em Ciências

Programa de Otorrinolaringologia

Orientador: Prof. Dr. Luiz Ubirajara Sennes

São Paulo

2016 


\section{Dados Internacionais de Catalogação na Publicação (CIP)}

Preparada pela Biblioteca da

Faculdade de Medicina da Universidade de São Paulo

Creprodução autorizada pelo autor

\section{Chagury, Azis Arruda}

Estudo da associação entre antígenos de histocompatibilidade leucocitária e penfigoide bolhoso em pacientes brasileiros / Azis Arruda Chagury. -- São Paulo, 2016.

Tese(doutorado)--Faculdade de Medicina da Universidade de São Paulo.

Programa de Otorrinolaringologia.

Orientador: Luiz Ubirajara Sennes.

Descritores: 1.Penfigoide bolhoso 2.Reação em cadeia da polimerase 3.Antígenos de histocompatibilidade classe I 4.Antígenos de histocompatibilidade Classe II 5.Alelos 6.Anticorpos

USP/FM/DBD-351/16 


\section{Dedico}

Aos meus pais, Omar e Maria Helena, pela construção dos pilares de moral e ética em minha vida; exemplos pessoais e profissionais. Fontes de amor e dedicação, fundamentais para minha formação e pelo caminho que escolhi.

À minha irmã Taís, por todo carinho, paciência e amor durante todos esses anos de convivência ao seu lado.

À minha esposa Karina, por toda compreensão, ajuda, amor $e$ companheirismo que me mantém feliz todos os dias. Seu apoio aos meus sonhos é o alicerce para eles se tornarem realidade. 


\section{AGRADECIMENTOS}

Agradeço ...

Ao Prof Dr. Ivan Dieb Miziara, pela oportunidade oferecida e pela introdução de duas novas áreas de atuação despertadas em mim. Fonte de conhecimento e exemplo a ser seguido.

Ao Prof. Dr. Luiz Ubirajara Sennes, Professor Associado e Coordenador do Programa de Pós-Graduação da Disciplina de Otorrinolaringologia da FMUSP, pela oportunidade oferecida e os ensinamentos da minha formação profissional e pessoal, que contribuíram no desenvolvimento e conclusão desta obra.

Ao Prof Dr. Ricardo Ferreira Bento, Professor Titular da Disciplina de Otorrinolaringologia da FMUSP, pela sua capacidade de liderança que contribuiu para o crescimento do departamento e de nossa especialidade.

Ao Dr. Hélcio Rodrigues e ao Prof. Dr. Jorge Kalil, do laboratório de Imunologia de Transplantes do InCor, que promoveram a realização prática em seu departamento.

Aos Profs. Drs. Rui Imamura, Ronaldo Frizzarini e Gilberto Guanaes Simões Formigoni pelas críticas construtivas realizadas durante o exame de qualificação e por todo conhecimento prático da minha formação médica.

Aos amigos Júlio Miranda Gil e Ali Mahmoud por todo o auxílio prestado durante o desenvolvimento do projeto.

À Claudia Borba Rosales, do Laboratório de Imunologia do InCOR, por auxiliar, orientar e explicar todo o processo de extração e tipificação de DNA. 
À amiga e professora Mariluci Lopes pela ajuda desde os anos de alfabetização e pela correção ortográfica do texto inicial.

Às Sras. Maria Marilede, Maria Márcia Alves e Lucivania Lima da Silva pelo carinho e atenção durante meu período de trabalho nessa Instituição.

Aos residentes, pós-graduandos e médicos assistentes do Departamento de Otorrinolaringologia da FMUSP pelo companheirismo, aprendizado e convivência prazerosa.

A todos os pacientes com os quais convivi durante todos os anos da minha formação que, em meio ao sofrimento, contribuíram para a ciência e aprendizado. Minha eterna gratidão.

À Coordenação de Aperfeiçoamento de Pessoal de Nível Superior (CAPES) pela bolsa de estudos oferecida. 
"A coisa mais indispensável a um homem é reconhecer o uso que deve fazer do seu próprio conhecimento."

Platão 


\section{SUMÁRIO}

Lista de Siglas

Lista de Abreviaturas

Lista de Símbolos

Lista de Figuras e Gráficos

Lista de Tabelas

Resumo

Abstract

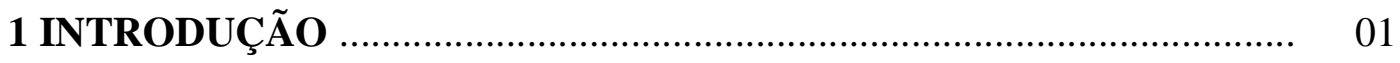

2 OBJETIVOS .................................................................................... 06

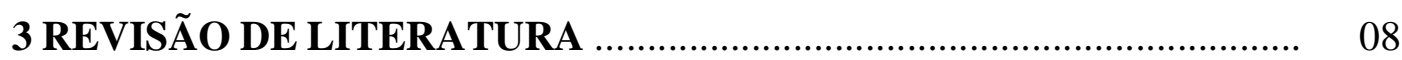

3.1 Desmossomo e hemidesmossomo ............................................................ 09

3.2 Penfigoide bolhoso ........................................................................... 10

3.2.1 Epidemiologia .......................................................................... 10

3.2.2 Quadro clínico ................................................................................. 11

3.2.3 Diagnóstico ................................................................................... 13

3.2.4 Fisiopatologia .............................................................................. 15

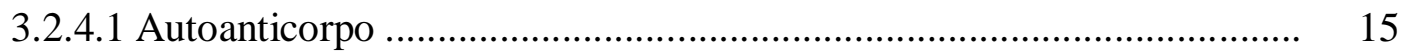

3.2.4.2 Fatores de indução ........................................................................... 17

3.2.4.3 Participação genética no penfigoide .................................................... 17

3.3 O complexo principal de histocompatibilidade (MHC) e o sistema antígeno leucocitário humano (HLA) .................................................. 18

3.4 Sistema HLA nas populações ............................................................. 20

3.4.1 HLA-DQB1*03:01 e as variantes do penfigoide ................................. 21

3.5 Genotipagem e o sistema HLA …....................................................... 22

3.6 A população brasileira ............................................................................... 23

4 CASUÍSTICA E MÉTODO ................................................................. 24

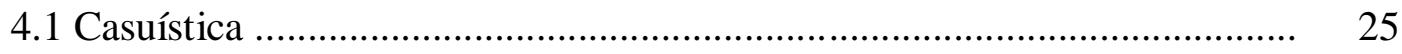

4.1.1 Aspectos éticos da pesquisa ......................................................... 25

4.1.2 Desenho do estudo ...................................................................... 25 
4.1.3 Local e população do estudo .............................................................. 25

4.1.4 Critérios de inclusão e exclusão ............................................................. 26

4.1.4.1 Critérios de inclusão .................................................................... 26

4.1.4.2 Critérios de exclusão ..................................................................... 26

4.1.5 Grupo controle ......................................................................... 26

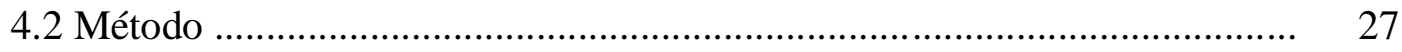

4.2.1 Coleta de amostra do sangue periférico ................................................... 27

4.2.2 Extração e tipificação do DNA ............................................................ 28

4.2.3 Extração de DNA do sangue pelo método QIAGEN ............................... 28

4.2.4 Tipificação HLA pelo método PCR-SSO …......................................... 30

4.2.5 Análise estatística ........................................................................ 31

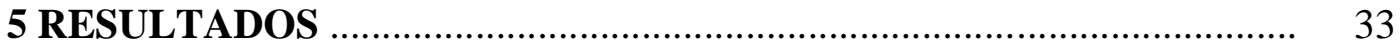

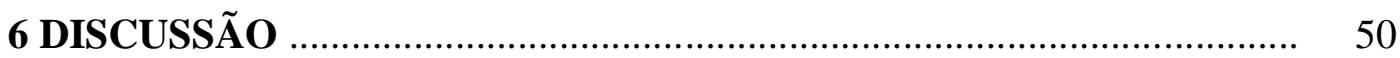

6.1 Associação HLA e a população brasileira .................................................. 54

7 CONCLUSÃO …......................................................................... 57

ANEXOS

Anexo A - Protocolo de tipagem para o Laboratório de Imunologia do InCor $\quad 60$

Anexo B - Tipificação HLA pelo método PCR-SSO ..................................... 61

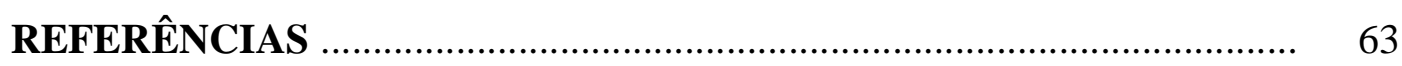

\section{APÊNDICES}

Apêndice 1 - Termo de Consentimento Livre e Esclarecido

Apêndice 2 - Termo de Aprovação do Comitê de Ética para Análise de Projetos de Pesquisa 


\section{LISTA DE SIGLAS}

FMUSP $\quad$ Faculdade de Medicina da Universidade de São Paulo

HC-FMUSP Hospital das Clínicas da Faculdade de Medicina da Universidade de São Paulo

InCor Instituto do Coração

USP Universidade de São Paulo 


\section{LISTA DE ABREVIATURAS}

BP180 bullous pemphigoid 180

BP230 bullous pemphigoid 230

C3 fração c3 do complemento

DNA deoxyribonucleic acid (ácido desoxirribonucleico)

EDTA ethylenediamine tetraacetic acid (ácido etilenodiamino tetraacético)

ELISA enzime-linked immunosorbent assay

et al. e outros

FDR false discovery rate (taxa de descobertas falsas)

hab. habitantes

HD hemidesmossomo

HLA human leukocyte antigen

IFD imunofluorescência direta

IFI imunofluorescência indireta

IgG imunoglobulina $\mathrm{g}$

LT linfócitos $\mathrm{t}$

MHC major histocompatibility complex (complexo principal de histocompatibilidade)

OR odds ratio (razão das chances)

PB penfigoide bolhoso

PCR polymerase chain reaction

RNA ribonucleic acid

$\mathrm{RR}$ risco relativo

SSO sequence-specific oligonucleotide (oligonucleotídeo sequência específica)

ZMB zona de membrana basal 


\section{LISTA DE SÍMBOLOS}

$\begin{array}{ll}{ }^{\circ} \mathrm{C} & \text { grau Celsius } \\ \mathrm{IC}_{95 \%} & \text { intervalo de confiança de } 95 \text { por cento } \\ \mathrm{kDa} & \text { quilodalton } \\ \mathrm{mL} & \text { mililitro } \\ \mathrm{mM} & \text { milimol } \\ \mathrm{nm} & \text { nanometro } \\ { }^{\circledR} & \text { marca registrada } \\ \mathrm{rpm} & \text { rotações por minuto } \\ \mathrm{TM} & \text { trademark } \\ v s . & \text { versus } \\ \mu \mathrm{L} & \text { microlitro } \\ < & \text { menor que } \\ \leq & \text { menor ou igual a } \\ \geq & \text { maior ou igual a } \\ = & \text { igual a } \\ \% & \text { por cento }\end{array}$




\section{LISTA DE FIGURAS E GRÁFICOS}

Figura 1 Estrutura molecular de um hemidesmossomos

Figura 2 Estrutura de um hemidesmossomo. (A) Imagem de microscopia eletrônica de pele contento hemidesmossomo. AF: Fibrilas de ancoragem; LL: Lâmina lúcida; LD: Lâmina densa; SDP: Placa sub-basal densa; OP: Placa externa; IP: Placa interna; IF: Filamentos intermediários. (B) Modelo esquemático de um hemidesmossomo e seus componentes .......

Figura 3 Manifestação clínica do penfigoide bolhoso, com bolha tensa, crostas e placas eritematosas

Figura 4 Lesão ulcerada em lábio inferior e gengiva

Figura 5 Simbléfaro em olho esquerdo

Figura 6 Exame anatomopatológico (Hematoxilina-Eosina 5x) com evidencia de formação de bolha subepitelial

Figura 7 Imagem de imunofluorescência direta de pele perilesional em paciente com penfigoide bolhoso. Depósito de C3 contínuo, linear, na zona da membrana basal

Figura 8 Representação esquemática do autoantígeno BPAG2

Figura 9 Visualização esquemática do cromossomo 6 e as classes I, II e III

Figura 10 Imagem do equipamento usado para centrifugação das amostras de sangue periférico

Figura 11 Processo de pipetagem de compostos usados para preparação das amostras de sangue periférico para extração de DNA

Figura 12 Aparelho LABScan ${ }^{\mathrm{TM}}$ 100, utilizado para promover a identificação da tipagem de HLA

Gráfico 1 Distribuição dos casos de penfigoide bolhoso incluídos no estudo segundo Estado de origem 
Gráfico 2 Distribuição dos casos de penfigoide bolhoso segundo fator desencadeante

Gráfico 3 Odds ratio (OR) dos alelos do HLA A para os pacientes com penfigoide bolhoso e os doadores de órgãos (controles), HCFMUSP, 2016

Gráfico 4 Odds ratio (OR) dos alelos do HLA B para os pacientes com penfigoide bolhoso e os doadores de órgãos (controles), HCFMUSP, 2016

Gráfico 5 Odds ratio (OR) dos alelos do HLA C para os pacientes com penfigoide bolhoso e os doadores de órgãos (controles), HCFMUSP, 2016

Gráfico 6 Odds ratio (OR) dos alelos do HLA DRB1 para os pacientes com penfigoide bolhoso e os doadores de órgãos (controles), HC-FMUSP, 2016

Gráfico 7 Odds ratio $(\mathrm{OR})$ dos alelos do HLA DQB1 alta definição para os pacientes com penfigoide bolhoso e os doadores de órgãos (controles), HC-FMUSP, 2016

Gráfico 8 Odds ratio (OR) dos alelos do HLA DQA1 alta definição para os pacientes com penfigoide bolhoso e os doadores de órgãos (controles), HC-FMUSP, 2016 


\section{LISTA DE TABELAS}

Tabela 1 Características dos pacientes com penfigoide bolhoso e dos doadores de órgãos (controles), HC-FMUSP, 2016

Tabela 2 Prevalência fenotípica dos alelos do HLA A para os pacientes com penfigoide bolhoso e os doadores de órgãos (controles), HC-FMUSP, 2016

Tabela 3 Prevalência fenotípica dos alelos do HLA B para os pacientes com penfigoide bolhoso e os doadores de órgãos (controles), HC-FMUSP, 2016

Tabela 4 Prevalência fenotípica dos alelos do HLA C para os pacientes com penfigoide bolhoso e os doadores de órgãos (controles), HC-FMUSP, 2016

Tabela 5 Prevalência fenotípica dos alelos do HLA DRB1 para os pacientes com penfigoide e os doadores de órgãos (controles), HC-FMUSP, 2016

Tabela 6 Prevalência fenotípica dos alelos do HLA DQB1 alta definição para os pacientes com penfigoide e os doadores de órgãos (controles), HC-FMUSP, 2016

Tabela 7 Prevalência fenotípica dos alelos do HLA DQA1 alta definição para os pacientes com penfigoide e os doadores de órgãos (controles), HC-FMUSP, 2016 


\section{RESUMO}

Chagury AA. Estudo da associação entre antígenos de histocompatibilidade leucocitária e penfigoide bolhoso em pacientes brasileiros [tese]. São Paulo: Faculdade de Medicina, Universidade de São Paulo; 2016.

INTRODUÇÃO: O penfigoide bolhoso é uma doença autoimune, vesicobolhosa com incidência de 0,2 a 1,4 por 100.000 hab. Sua fisiopatologia caracteriza-se pela ação de autoanticorpos na junção dermoepidérmica dos hemidesmossomos, promovendo a formação de bolhas subepidérmicas na pele e mucosas. Estudos vêm sendo publicados demonstrando a associação de penfigoide com alelos do sistema HLA classe II em diferentes populações do mundo, entretanto não há dados sobre a população brasileira, uma das mais heterogêneas do mundo. PACIENTES E MÉTODOS: O grupo de estudo incluiu 17 pacientes brasileiros com diagnóstico confirmado de PB de um hospital na cidade de São Paulo, sudeste do Brasil. O DNA foi extraído a partir de sangue periférico utilizando kits Qiagen (QIAamp DNA Mini Kit ${ }^{\circledR}$ ) e a tipagem HLA loci A, B, C, DR e DQ foi realizada por meio de PCR e a amplificação utilizando o oligonucleótido de sequência específica (SSO) contido nos kits LABType ${ }^{\circledR}$. O grupo controle foi composto por um banco de dados de 297 doadores falecidos da cidade de São Paulo. Este banco de dados é parte do Sistema de Transplantes da Secretaria de Saúde do Governo do Estado de São Paulo. RESULTADOS: Os resultados mostram que os alelos HLA C*17, DQB1*03:01, DQA1*01:03 e DQA1*05:05 estão associados com o aparecimento da doença na população brasileira, com risco relativo de 8,31 (2,46 a 28,16), 3,76 (1,81 a 7,79), 3,57 (1,53 a 8,33) e 4,02 (1,87 a 8,64), respectivamente ( $\mathrm{p}<0,005)$. O nível de significância estatística foi ajustado utilizando a correção de Bonferroni, dependendo das frequências fenotípicas avaliadas para HLA de classe I (A, B e C) e classe II (DRB1, DQB1 e DQA1). DISCUSSÃO: Os dados indicam que pacientes brasileiros com $\mathrm{PB}$ apresentam a mesma predisposição genética ligada ao HLA-DQB1*03:01 relatado anteriormente em caucasianos e indivíduos iranianos e o estudo apresenta três novos alelos (C*17, DQA1*01:03 e DQA1* 05:05) envolvidos na fisiopatologia da PB. CONCLUSÕES: Os resultados mostram que os alelos HLA C*17, DQB1*03:01, DQA1*01:03 e DQA1*05:05 estão associados com $\mathrm{o}$ aparecimento da doença na população brasileira.

Descritores: penfigoide bolhoso; reação em cadeia da polimerase; antígenos de histocompatibilidade classe I; antígenos de histocompatibilidade classe II; alelos; anticorpos 


\begin{abstract}
Chagury AA. Study of the association between human leukocyte antigens (HLA) and bullous pemphigoid in Brazilian patients [Thesis]. São Paulo: "Faculdade de Medicina, Universidade de São Paulo"; 2016.
\end{abstract}

BACKGROUND: Bullous pemphigoid (BP) is an autoimmune disease with bullous vesicles and an incidence of 0.2 to 1.4 per 100,000 inhabitants. Its pathophysiology is characterized by the action of autoantibodies on hemidesmosomes at the dermalepidermal junction, promoting subepidermal blister formation in the skin and mucous membranes. Many studies have been published demonstrating the association of pemphigoid with HLA class II system alleles in different populations, however there are no data on the Brazilian population, one of the most heterogeneous in the world. PATIENTS AND METHODS: The study group included 17 Brazilian patients with a confirmed diagnosis of BP from a hospital in Sao Paulo city, southeast Brazil. DNA was extracted from peripheral blood using Qiagen kits (QIAamp DNA Mini Kit ${ }^{\circledR}$ ) and HLA A, B, C, DR and DQ typing was performed using PCR and amplification using Sequence-Specific Oligonucleotide (SSO) contained in LABType ${ }^{\circledR}$ kits. The control group was composed of a database of 297 deceased donors from the city of São Paulo. This database is part of the Transplants State System of the Government's Health Secretary from the State of Sao Paulo. RESULTS: Our findings show that alleles HLA C*17, DQB1*03:01, DQA1*01:03 and DQA1*05:05 are associated with the onset of the disease in the Brazilian population, with relative risks of 8.31 (2.46 to 28.16), 3.76 (1.81 to 7.79 ), 3.57 (1.53 to 8.33), and 4.02 (1.87 to 8.64), respectively ( $\mathrm{p}<0.005$ ). The statistical significance level was adjusted using the Bonferroni correction depending on the phenotypic frequencies evaluated for HLA class I (A, B and C) and class II (DRB1, DQB1 and DQA1). DISCUSSION: Our data indicate that Brazilian patients with BP present the same genetic predisposition linked to HLA-DQB1*03:01 previously reported in Caucasian and Iranian individuals and our study introduces three new alleles (C*17, DQA1*01:03 and DQA1*05:05) involved in the pathophysiology of BP. CONCLUSIONS: Our findings show that alleles HLA $C^{*} 17$, DQB1*03:01, DQA1*01:03 and DQA1*05:05 are associated with the onset of the disease in the Brazilian population.

Descriptors: pemphigoid, bullous; polymerase chain reaction; histocompatibility antigens class I; histocompatibility antigens class II; alleles; antibodies. 
1 INTRODUÇÃO 


\section{INTRODUÇÃO}

O penfigoide bolhoso (PB) é uma doença autoimune caracterizada por vesículas subepidérmicas que ocorrem, mormente em idosos, entre 60 e $70 \operatorname{anos}^{[1,2]}$. O próprio nome "penfigoide bolhoso" é um pleonasmo, pois é derivado do grego (pemphix $=$ bolha e eidos $=$ forma $)$. Entretanto, o adjetivo "bolhoso" permite distinguilo de outras doenças que também pertencem ao grupo dos pemphigoids, tais como penfigoide gestacional e penfigoide de membranas mucosas ${ }^{[3]}$.

A incidência anual do PB é calculada entre 0,2 e 1,4 por 100.000 pessoasano $^{[4-7]}$, com estimativa de aumentar esse valor conforme o envelhecimento da população. Um estudo francês recente evidenciou o triplo desse valor ao longo de 15 anos, e mostrou uma incidência de 2,1 por 100.000 pessoas-ano ${ }^{[8]}$, justificável por causa do aumento da expectativa de vida.

A fisiopatologia do PB caracteriza-se pela ação de autoanticorpos na junção dermoepidérmica contra antígenos específicos nos hemidesmossomos ${ }^{[9]}$ e causa, deste modo, a separação da epiderme da derme.

Para entender a fisiopatologia do PB, é necessário compreender a estrutura de um hemidesmossomo ${ }^{[10]}$. Ele é composto por diversas moléculas, como a BP230, BP180 ou colágeno (COL) XVII, integrina $\alpha 6$ e $\beta 4$, plectina e proteína tetraspanina $\mathrm{CD} 151^{[10]}$. O complexo hemidesmossomal interage com as queratinas 5/14 dentro do citoplasma e com a laminina 332, o colágeno IV e colágeno VII, na matriz extracelular (Figura 1) ${ }^{[11]}$. 


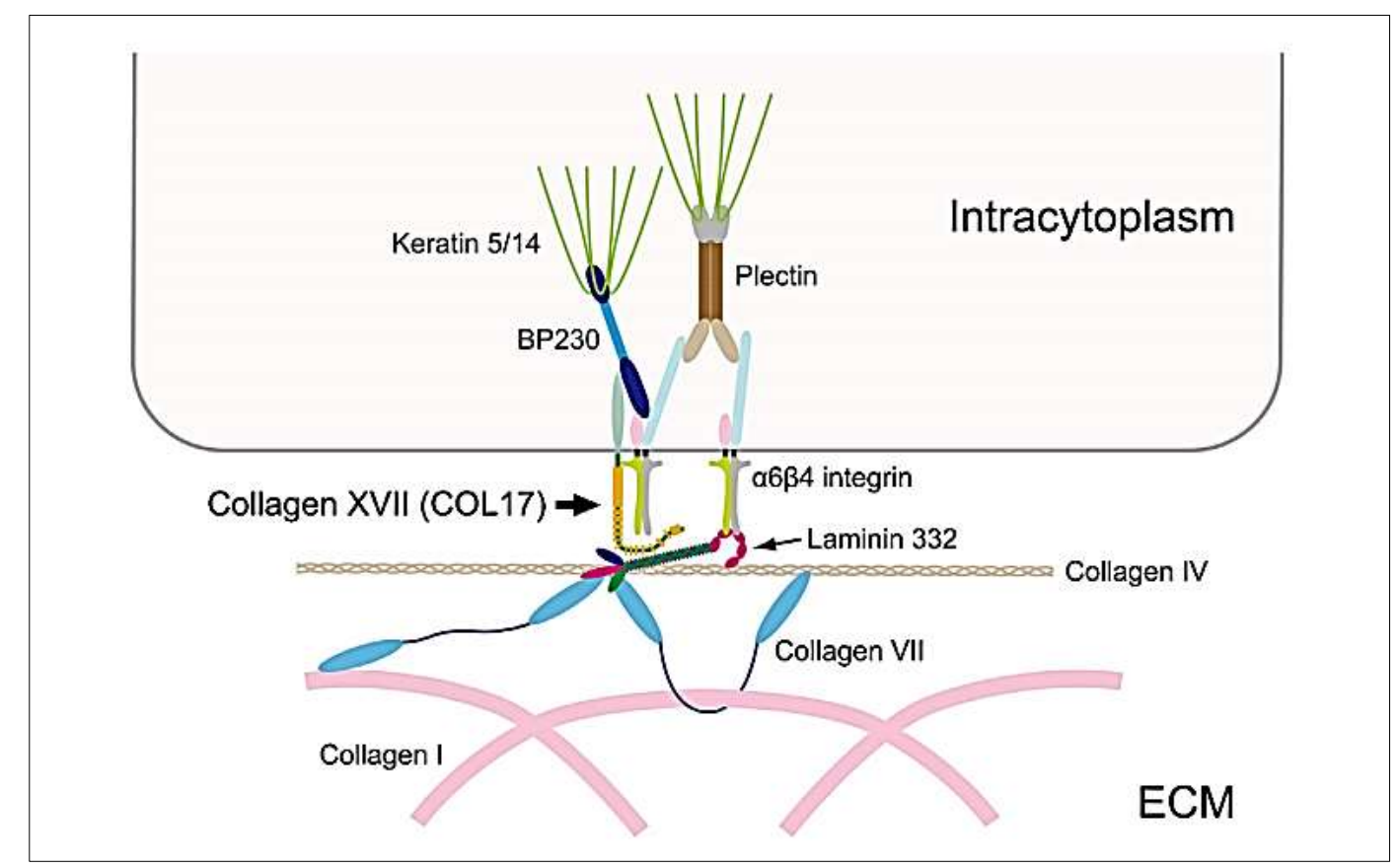

Figura 1. Estrutura molecular de um hemidesmossomo (Fonte: Nishie, 2014 ${ }^{[11]}$ ).

A resposta imunológica do PB, dessa forma, é caracterizada pela presença dos autoanticorpos circulantes $\mathrm{IgG}$ e $\mathrm{C} 3$ contra os componentes estruturais da zona da membrana basal $(\mathrm{ZMB})^{[12,13]}$. Esses autoanticorpos têm dois alvos principais, o antígeno 1 (BPAG1, também conhecido por BP230) e antígeno 2 (BPAG2, BP180 ou colágeno tipo XVII) ${ }^{[13-15]}$.

Os linfócitos T e B, além disso, possuem função importante na indução e regulação das respostas celular e humoral, envolvidas na gênese do $\mathrm{PB}^{[16,17]}$. Os linfócitos $\mathrm{T}$ expressam marcadores de memória na superfície de células T CD4+ e exibem um perfil misto de citocinas Th1 e Th2 $2^{[16]}$.

As citocinas Th1 (como IFN-y) são capazes de induzir a secreção de IgG1 e IgG2, ao passo que as citocinas Th2 (tais como IL-4, IL-5, e IL-13) mantêm o papel 
de regular a secreção de IgE e IgG4 circulantes. Portanto, a detecção de anticorpos anti-BP180 e anti-BP230 dos isótopos IgG1, IgG4 e IgE em pacientes com PB sugere que ambas as células Th1 e Th2 estão envolvidas na regulação da resposta aos antígenos alvo do $\mathrm{PB}^{[18,19]}$.

Um dos métodos mais utilizados para identificar os possíveis genes participantes dessa susceptibilidade, têm sido por meio de estudos do tipo casocontrole, utilizando-se bases populacionais entre diversos países.

Esses estudos envolvem o sistema antígeno leucocitário humano (HLA - do inglês, Human Leukocyte Antigen), que consiste de um conjunto de genes responsável pela codificação das moléculas de histocompatibilidade (MHC - do inglês, Major Histocompatibility Complex).

As funções principais das moléculas de HLA estão na apresentação aos linfócitos $\mathrm{T}$, e podem ser dos pequenos peptídeos, derivados das proteínas do próprio organismo ou de patógenos ${ }^{[20]}$.

Paralelamente, diversos estudos estão sendo publicados anualmente e mostram a associação de PB com alelos do sistema HLA classe II, em diferentes populações do mundo. Porém, esses alelos identificados não são necessariamente os mesmos nas diferentes populações investigadas e são encontrados, por exemplo, alelos como fatores de proteção ou que predispõem ao surgimento da doença, e justificam, portanto, a sua identificação em diferentes populações. Em alguns estudos da Europa e Ásia, por exemplo, em relação às moléculas da classe I loci $\mathrm{A}, \mathrm{B}$ e $\mathrm{C}$, não foram encontradas diferenças significativas entre o grupo de PB e o grupo controle ${ }^{[21-23]}$, porém, nas de classe II - DR e DQ foram encontrados resultados expressivos. 
$\mathrm{Na}$ população brasileira ainda não tinha sido feita nenhuma pesquisa que envolvesse a associação entre os alelos de pacientes com PB e a população sem manifestação da doença. O presente estudo é, portanto, inédito na literatura mundial sobre os alelos nessa população. 
2 OBJETIVO 


\section{OBJETIVO}

O objetivo do presente estudo é avaliar a associação dos alelos do sistema HLA

(loci A, B, C, DR e DQ) de pacientes brasileiros portadores de penfigoide bolhoso, mediante a comparação da prevalência desses alelos com a de um grupo de doadores de órgãos (controles). 
3 REVISÃO DE LITERATURA 


\section{REVISÃO DE LITERATURA}

\subsection{Desmossomo e hemidesmossomo}

Os desmossomos foram descritos inicialmente, em 1872, por um patologista italiano, Bizzozero ${ }^{[24]}$. Todavia, o termo "desmossoma" foi cunhado, a princípio, pelo anatomista austríaco Josef Schaffer ${ }^{[25]}$, que combinou as palavras gregas desmos (ligação) e soma (corpo). Porém, a primeira análise detalhada da ultraestrutura dos desmossomos foi publicada por Odland ${ }^{[26]}$, em 1958.

Os desmossomos são junções discoides com diâmetro de 0,2-0,5 $\mu \mathrm{m}$, compostos por duas placas eletrodensas, separadas por um espaço de $24 \mathrm{~nm}$ a $30 \mathrm{~nm}^{[26]}$. Estão intimamente associados à adesão intercelular e patogênese de outras doenças bolhosas, como o pênfigo vulgar ${ }^{[27]}$.

Os hemidesmossomos (HD) são estruturas mediadas por integrinas, responsáveis pela aderência entre o epitélio e a membrana basal (Figura 2). Existem dois tipos principais de HDs, o tipo I e o tipo II, que podem ser diferenciados por meio de seus componentes de proteína ${ }^{[28]}$. O primeiro tipo, encontrado em tecido estratificado e pseudoestratificado, por exemplo, na epiderme e que consiste de cinco componentes principais: as integrina $\alpha 6 \beta 4$, plectina $1^{\mathrm{a}}(\mathrm{P} 1 \mathrm{a})$, tetraspanina CD151, BPAG1 e BPAG2 ${ }^{[29]}$. O do tipo II é encontrado no epitélio simples, como no intestino, cuja formação ocorre graças à integrina $\alpha 6 \beta 4$ e plectina ${ }^{[30]}$. 


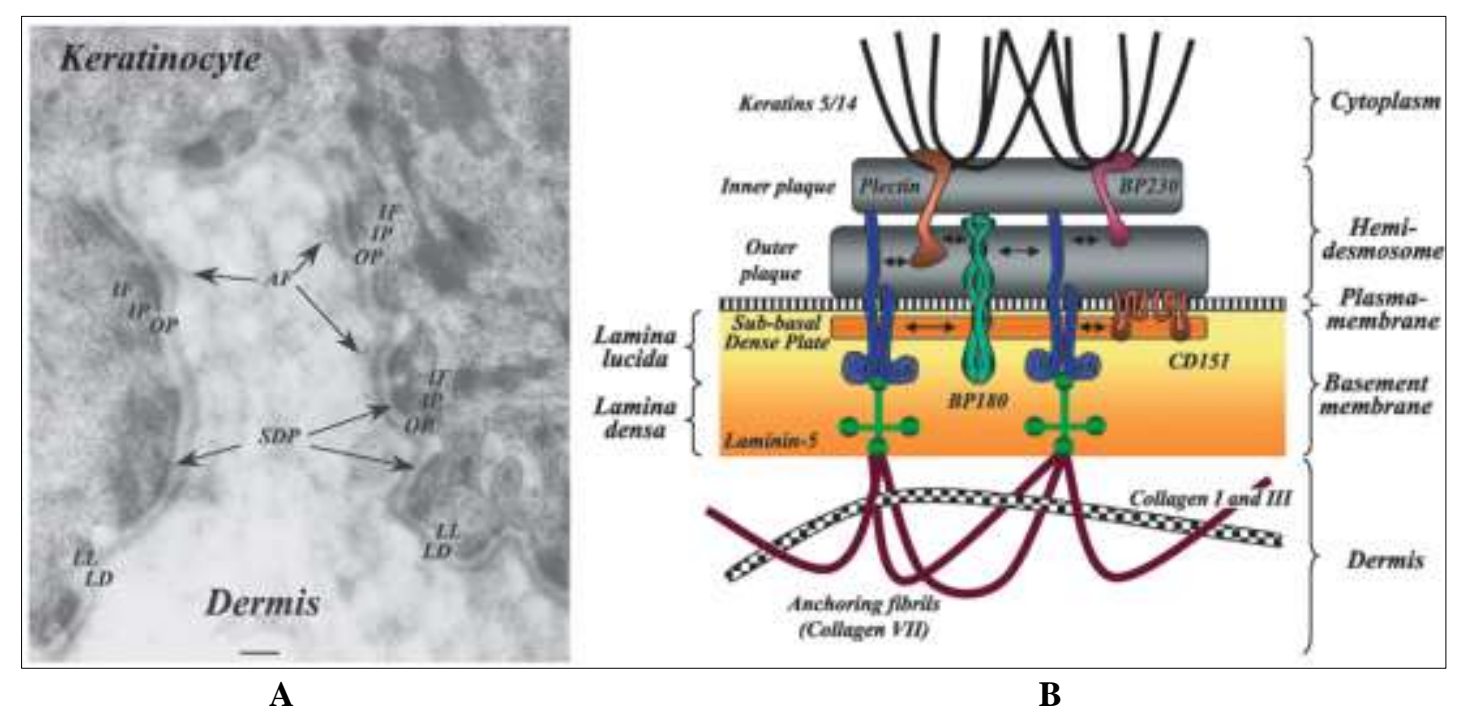

Figura 2. Estrutura de um hemidesmossomo. (A) Imagem de microscopia eletrônica de pele que contém um hemidesmossomo. AF: Fibrilas de ancoragem; LL: Lâmina lúcida; LD: Lâmina densa; SDP: Placa sub-basal densa; OP: Placa externa; IP: Placa interna; IF: Filamentos intermediários. (B) Modelo esquemático de um hemidesmossomo e seus componentes. (Fonte: Fontao et al., $1999^{[31]}$ )

\subsection{Penfigoide bolhoso}

\subsubsection{Epidemiologia}

Os dados demográficos do PB variam conforme a região do mundo. Na Europa são relatadas incidências anuais de PB por milhão de habitantes: 0,047 na Turquia ${ }^{[32]}$, 2,5 na Romênia ${ }^{[33]}$, 4,47 na Polônia ${ }^{[34]}, 10$ na Itália ${ }^{[35]}$ e 42,8 no Reino Unido ${ }^{[5]}$.

Uma comparação importante está na publicação de dois estudos franceses, com características demográficas semelhantes, que mostra o triplo de aumento na incidência de PB no período de 15 anos; de $7,4^{[4]}$ para $21,7^{[8]}$ por milhão de habitantes e sugere que, tanto o próprio envelhecimento da população como exposições à outros 
fatores (como vacinas, vírus, medicações, etc.), sejam responsáveis pelo aumento da incidência de PB.

Na Ásia, são relatadas incidências anuais de PB por milhão de habitantes de: 2,6 no Kuwait ${ }^{[36]}$, 7,6 em Singapura ${ }^{[37]}$ e 23,6 em Israel ${ }^{[38]}$. Na África, existe apenas um estudo sobre esse dado e cita incidência de 3,84 por milhão de habitantes ${ }^{[39]}$. Com relação ao gênero, todos os estudos apontam uma predominância maior no gênero feminino, com exceção ao estudo de Zaara et al. (2011) ${ }^{[39]}$ para indivíduos africanos. No Brasil, não há dados demográficos estimados sobre a incidência de PB.

\subsubsection{Quadro clínico}

O quadro clínico apresenta-se muito variável. O PB acomete especialmente a pele, e em aproximadamente $10-25 \%$ a mucosa oral ${ }^{[40,41]}$. Geralmente a doença tem história crônica, inicia pela fase não bolhosa, manifesta-se com prurido intenso e pode ser acompanhado por eczema, eritema e pápulas (Figura 3). Pode persistir por vários meses ou como única manifestação da doença, nos casos atípicos ${ }^{[40,42]}$. Uma vez formadas, as bolhas podem ser largas e tensas, redondas ou ovaladas, localizadas ou generalizadas, com conteúdo sero-hemático. Frequentemente, podem romper-se e causar erosões (Figura 4), crostas e cicatrizes ${ }^{[42]}$. 


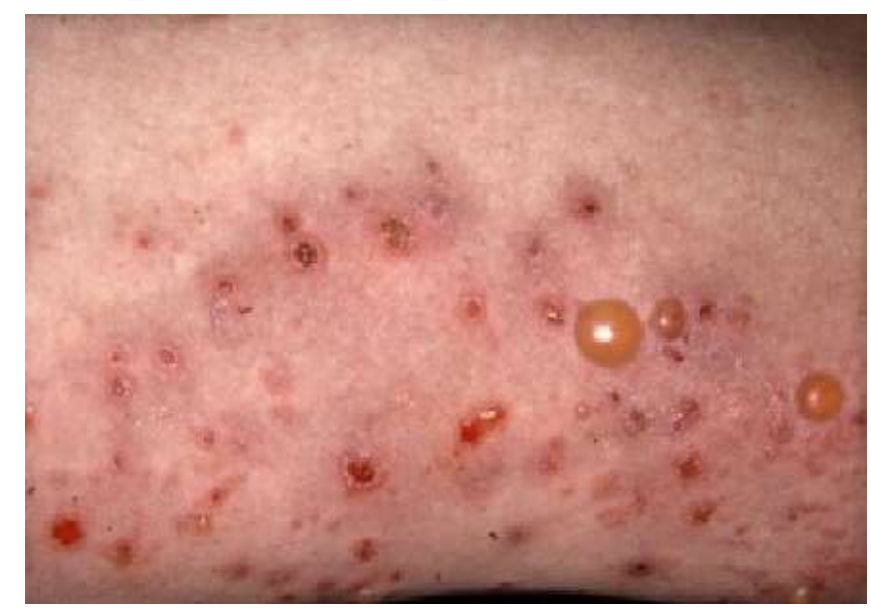

Figura 3. Manifestação clínica do penfigoide bolhoso, com bolha tensa, crostas e placas eritematosas. (Fonte: Mihalyi, 2012 $2^{[43]}$ )

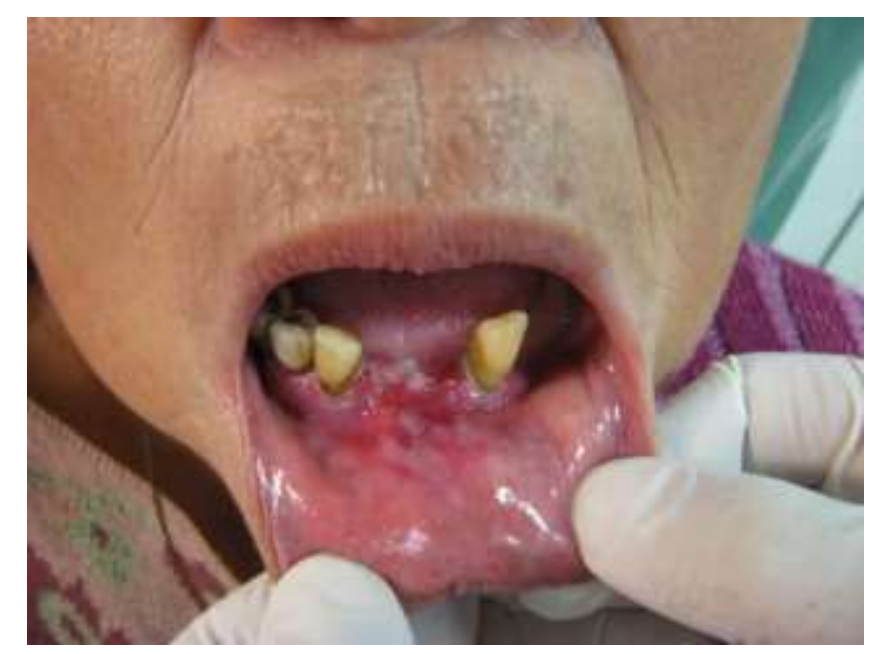

Figura 4. Lesão ulcerada em lábio inferior e gengiva. (Fonte: Ambulatório de Estomatologia do HC-FMUSP)

Os locais mais frequentes de aparecimento das bolhas são o tórax, as extremidades flexoras, as axilas e a região inguinal, entretanto, podem manifestar-se nos olhos (Figura 5), no nariz, na faringe, no esôfago e na área anogenital ${ }^{[44-46]}$. 


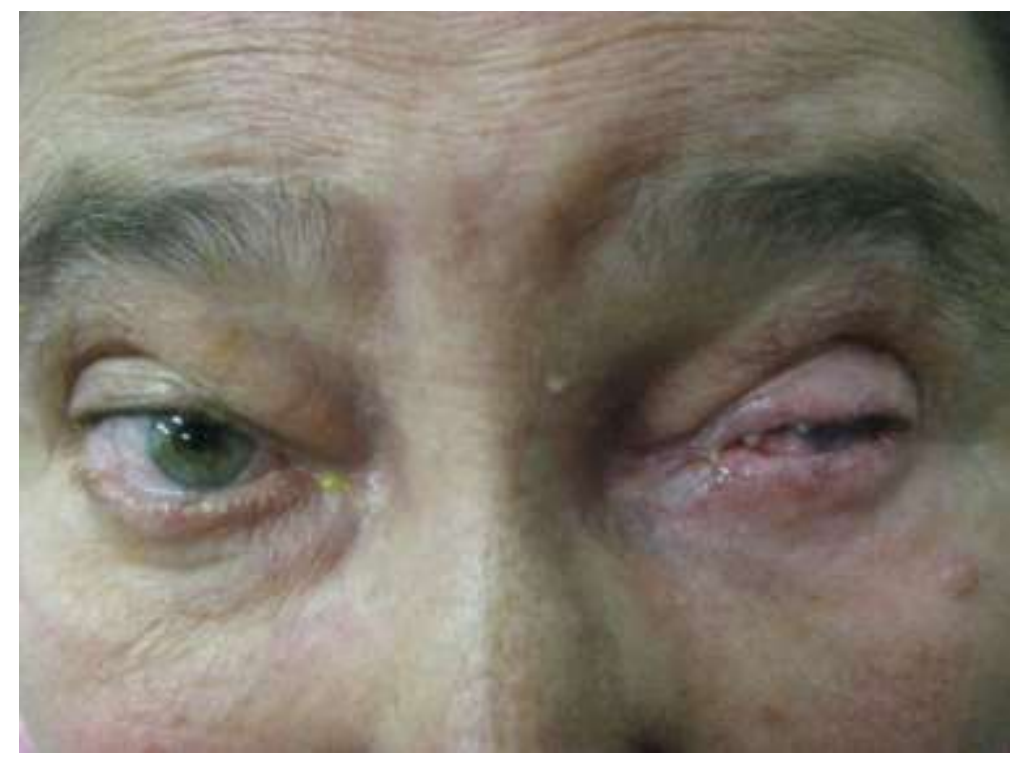

Figura 5. Simbléfaro em olho esquerdo. (Fonte: Ambulatório de Estomatologia do HC-FMUSP)

\subsubsection{Diagnóstico}

O quadro clínico das lesões vesicobolhosas e mucocutâneas podem ser extremamente semelhantes, o que dificulta a realização do diagnóstico apenas pela anamnese e pelo exame clínico. Dessa forma, para melhor elucidação da moléstia, são indicados os exames histopatológicos e imunológicos, realizados por meio de biópsia perilesional $^{[40]}$.

O exame histopatológico pode ser típico ou sugestivo no diagnóstico diferencial. De um modo geral, nas lesões bolhosas, a biópsia deve incluir, preferencialmente, a bolha toda ou ser perilesional. A característica principal no exame é a observação da formação de fendas ou bolhas subepiteliais (Figura 6), porém, não são achados exclusivos do $\mathrm{PB}^{[40,47]}$. 


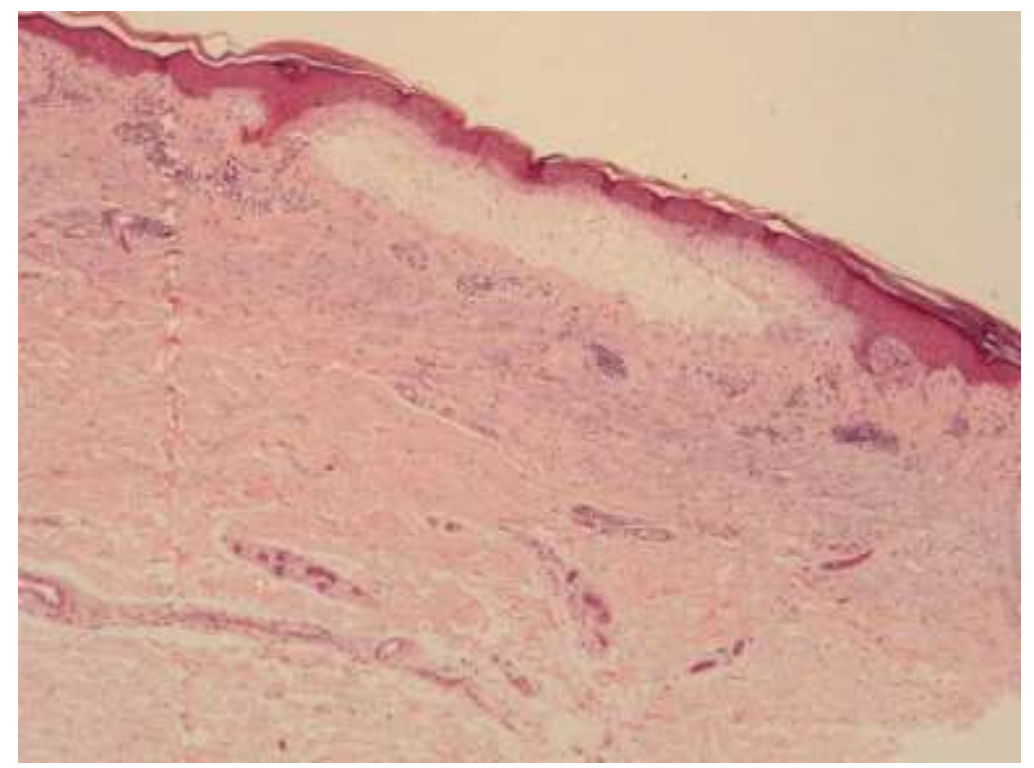

Figura 6. Exame anatomopatológico (Hematoxilina-Eosina 5x) com evidência de formação de bolha subepitelial. (Fonte: Departamento de Patologia do HC-FMUSP)

De forma complementar, na suspeita de lesão bolhosa mucocutânea, é realizado o exame de imunofluorescência direta (IFD) da lesão, que evidencia depósito linear de IgG e/ou C3 na zona de membrana basal (Figura 7). 


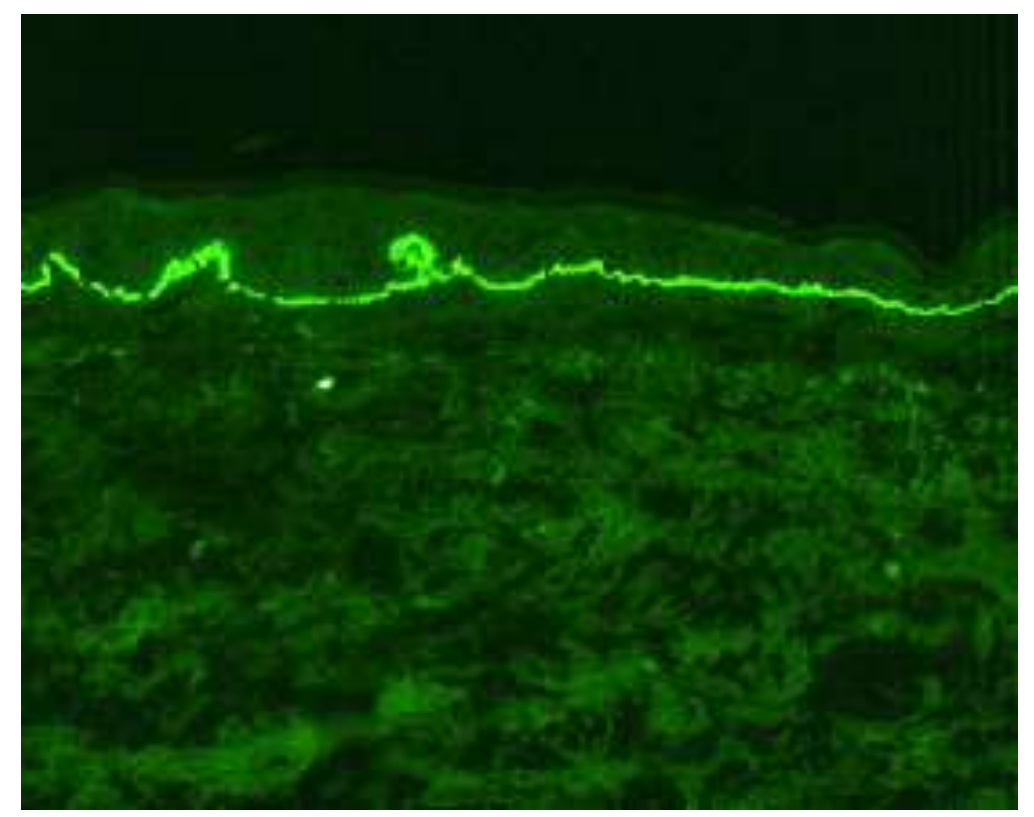

Figura 7. Imagem de imunofluorescência direta de pele perilesional em paciente com penfigoide bolhoso. Depósito de C3 contínuo, linear, na zona da membrana basal. (Fonte: Schmidt, dela Torre, Borradori, 2011 ${ }^{[42]}$ )

Algumas doenças bolhosas podem apresentar a IFD semelhante ao PB. Neste caso, pode-se utilizar um tipo de imunofluorescência indireta (IFI), o salt-split test, que é o "padrão-ouro" no diagnóstico de PB. É uma ferramenta diagnóstica mais sensível para a detecção do nível (lado epidérmico ou dérmico) de anticorpos na zona de membrana basal (ZMB), em dermatoses bolhosas subepiteliais ${ }^{[48,49]}$.

\subsubsection{Fisiopatologia}

\subsubsection{Autoanticorpos}

A característica principal da fisiopatologia do PB consiste na presença dos autoanticorpos circulantes contra os componentes da $\mathrm{ZMB}^{[9,50]}$, pois os anticorpos anti-hemidesmossomos, juntamente com os componentes do complemento são 
depositados na membrana basal na junção dermoepidérmica da pele e/ou mucosa lesionada ${ }^{[51]}$. Testes com imunoprecipitação mostram que esses autoanticorpos têm como alvo principal dois componentes do HD, o BP230 (BPAG1, também conhecido por antígeno 1) e o BP180 (BPAG2, antígeno 2 ou colágeno tipo XVII) ${ }^{[13-15]}$.

O BPAG1 possui peso molecular de 230kDa. É uma desmoplaquina encontrada na porção intracelular do hemidesmossomo e o seu gene está localizado no braço curto do cromossomo $6^{[52]}$. O BPAG2 (Figura 8) corresponde a uma glicoproteína transmembrana que se deposita na porção superior da lâmina lúcida, com peso molecular de 180kDa. Contém quinze domínios que pertencem ao carboxi-terminal que se estende até a lâmina lúcida, e um domínio não-colagenoso, o NC16 ${ }^{[17]}$, encontrado adjacente ao aspecto da transmembrana, presente em $90 \%$ dos pacientes $\operatorname{com} \mathrm{PB}^{[17,52,53]}$.

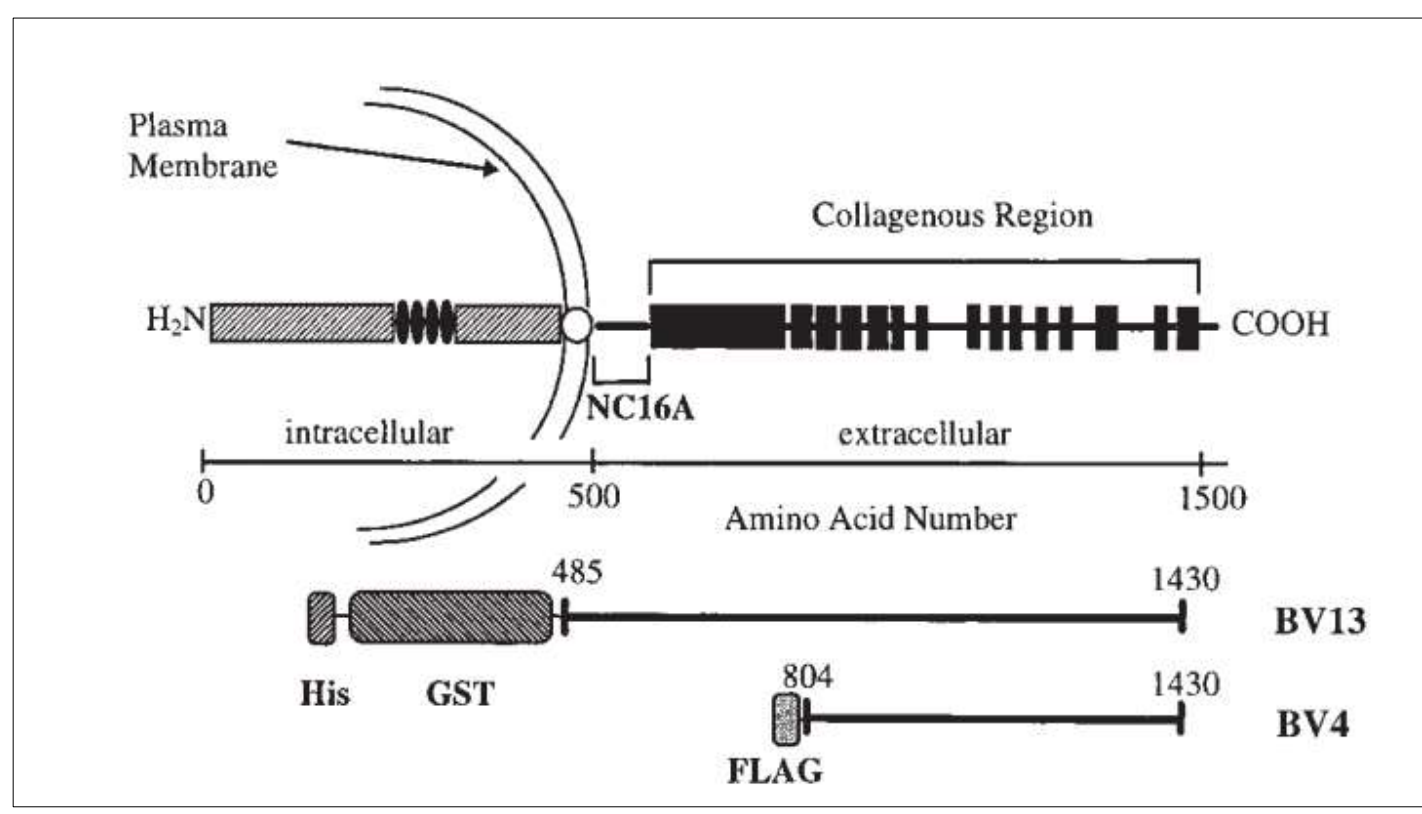

Figura 8. Representação esquemática do autoantígeno BPAG2. (Fonte: Budinger et al., 1998 ${ }^{[17]}$ ) 


\subsubsection{Fatores de indução}

Além da predisposição genética, foram observados diversos fatores que contribuem para o desenvolvimento do PB.

Algumas drogas podem agir como gatilhos em alguns pacientes com suscetibilidade genética, modificando a resposta imune ou alterando as propriedades da $\mathrm{ZMB}^{[54]}$. As drogas principais relacionadas com a doença são: penicilamina ${ }^{[55]}$, captopril $^{[56]}$, penicilina e derivados ${ }^{[57]}$ e a furosemida ${ }^{[1]}$.

Outro fator importante na indução do PB foi associado à vacinação. Nos últimos anos, em torno de 20 casos foram relacionados na pós vacinação, mormente pós vacina anti-influenza ${ }^{[58]}$.

Além dos citados, também foram enumerados outros fatores indutores de PB, tais como a radiação $\mathrm{UV}^{[59]}$, as queimaduras térmicas ${ }^{[60,61]}$, os procedimentos cirúrgicos $^{[62]}$, a radioterapia ${ }^{[63]}$, os transplantes ${ }^{[64]}$ e as infecções virais, notadamente, neste último caso, pelo herpes vírus ${ }^{[65]}$.

\subsubsection{Participação genética no penfigoide}

A produção de anticorpos pelos linfócitos B requer a participação dos linfócitos Th CD4+. Nos pacientes com PB, os autoantígenos da ZMB (BP180 e BP230) são capturados pela célula apresentadora de antígenos, processados, ligados ao complexo de histocompatibilidade principal (MHC) classe II e exibidos na superfície da célula. O reconhecimento mediado pelo receptor destes epitopos é feito pelas células T, que desencadeiam a liberação de várias citocinas e, consequentemente, estimulam as células B para produzir anticorpos ${ }^{[66]}$. 
Os genes HLA são, provavelmente, o fator de predisposição genética mais significativo, por causa de seu papel no processo de apresentação de antígenos. Muitos estudos mostram uma associação entre HLA-DQ $\beta 1 * 0301$ e os subtipos de penfigoide ${ }^{[66]}$.

Atualmente, é preciso compreender como se processa e onde ocorre a ativação das células B autorreativas, para o início da produção de autoanticorpos.

\subsection{O complexo principal de histocompatibilidade (MHC) e o sistema antígeno leucocitário humano (HLA)}

O complexo principal de histocompatibilidade (MHC - do inglês, Major Histocompatibility Complex) é o conjunto de genes responsável por codificar as moléculas de histocompatibilidade de uma determinada espécie. Na humana é denominada de sistema HLA (Human Leukocyte Antigen) ${ }^{[67]}$. No HLA, que está localizado no braço curto do cromossomo 6 com aproximadamente 224 genes, 51 desses genes estão envolvidos na resposta imune. Apresentam-se organizados nas regiões de HLA classe I, II e III (Figura 9). 


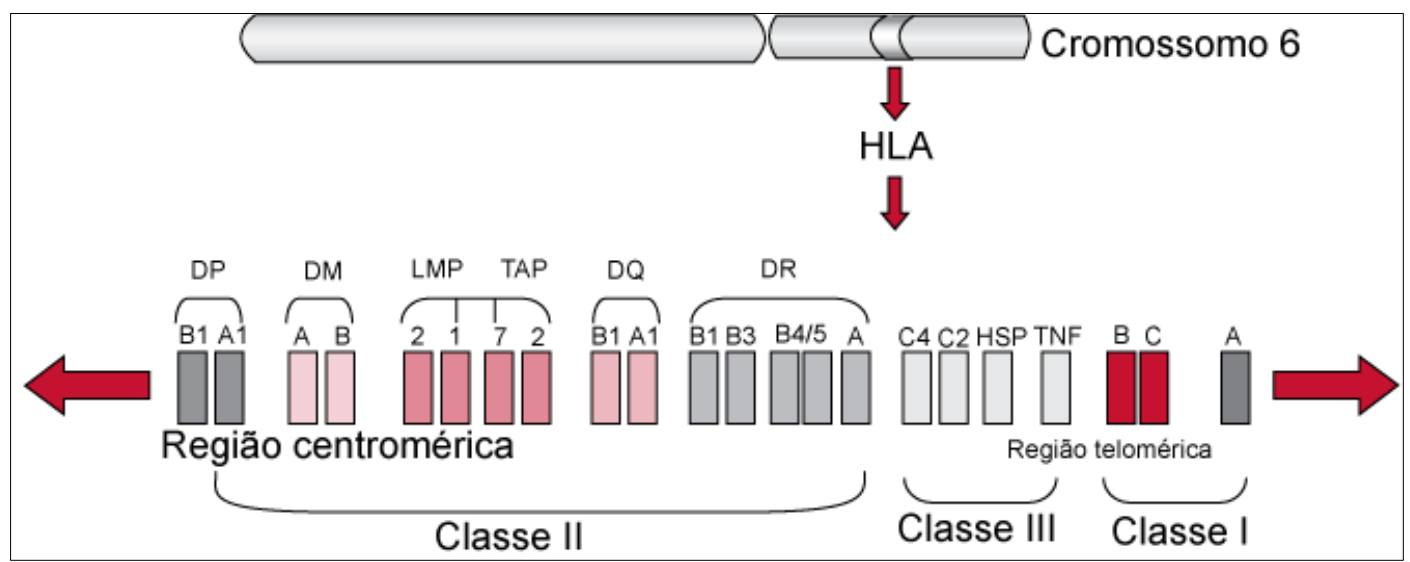

Figura 9. Visualização esquemática do cromossomo 6 e as classes I, II e III. (Fonte: adaptado de Reveille, 2006 ${ }^{[68]}$ )

As regiões HLA de classe I e II codificam proteínas expressas na superfície celular com grande polimorfismo genético. Entretanto, a região HLA de classe III não codifica essas moléculas de histocompatibilidade do sistema imune; não são, portanto, analisadas nos estudos da relação entre HLA e PB.

Diversos estudos têm sido publicados anualmente, e mostram a associação de PB com alelos do sistema HLA classe II, em diferentes populações do mundo. Entretanto, com relação às moléculas classe I, e loci A, B e C não foram encontradas diferenças significativas entre o grupo com PB e o grupo controle ${ }^{[21,69]}$.

As moléculas de classe II do sistema HLA são expressas em um grupo de células do sistema imune, que incluem monócitos/macrófagos, células dendríticas, células epiteliais tímicas, linfócitos B e linfócitos T ativados e atuam no processamento e na apresentação de proteínas extracelulares ${ }^{[20]}$. As moléculas são compostas por duas cadeias polipeptídicas $\alpha$ e $\beta$ associadas não covalentes, ambas codificadas por genes do MHC. 
A designação dos seus loci no cromossomo 6 consiste de três letras: a primeira (D), indica a classe; a segunda (M, O, P, Q ou R), a família, e a terceira, (A ou B) a cadeia ( $\alpha$ ou $\beta$, respectivamente). HLA-DQB, por exemplo, refere-se a genes classe II da família $Q$, que codifica as cadeias $\beta$. Os genes individuais são diferenciados por algarismos arábicos, e as variantes alélicas desses genes são representadas pelo número precedido por um asterisco. Por exemplo, HLA-DQB1*0301 se refere à variante alélica 0301 do gene 1 , o qual codifica a cadeia $\beta$ de uma molécula classe II pertencente à família $\mathrm{Q}^{[70]}$.

\subsection{Sistema HLA nas populações}

O sistema HLA é objeto de estudo para identificar os alelos envolvidos na patogênese de diversas doenças, tais como estomatite aftoide recorrente, líquen plano, pênfigo vulgar, penfigoides e seus subtipos ${ }^{[71-73]}$.

Um estudo de Delgado et al. (1996) ${ }^{[74]}$ com pacientes caucasianos que apresentavam diagnóstico de $\mathrm{PB}$, mostra associação estatisticamente significativa no HLA-DQB1*03:01, e em relação ao controle. Foram avaliados 21 pacientes com diagnóstico de PB e 218 pacientes saudáveis. A frequência do alelo HLADQB1*03:01 encontrada pelos autores foi de 35,7\% dos casos em comparação com $16,05 \%$ do controle $(p=0,005)^{[74]}$.

Em um outro estudo simultâneo com a população japonesa foram analisados os genes HLA-DR e -DQ em 23 casos com PB, e os pesquisadores obtiveram um aumento 
significativo de HLA-DRB1*04 (*0403, *0406)/DQA1*0301/DQB1*0302 e DRB1*1101/DQA1*0505/DQB1*0302 haplótipos, bem como os alelos individuais DRB1*1101 e DQB1*0302 (corrigido $p<0,05$ para cada comparação), quando conferidos com os controles ${ }^{[75]}$.

Por outro lado, pesquisa feita com a população chinesa evidenciou um fator de proteção em pacientes com PB ligado aos loci DRB1*08 (DR8) e DRB1*08/DQB1*06 (DR8/DQ6) em relação ao grupo controle (4,08\% vs. $15,19 \%$ e $1,54 \%$ vs. $13,82 \%$, respectivamente; $p<0,05)$, e mostrou não só a relação dos haploides de risco ligados à doença, bem como o fator de proteção ${ }^{[76]}$.

Em pesquisa iraniana recente, foram estudados 50 pacientes com PB e 180 controles, e foi observada uma frequência significativamente maior de HLADQA1*05:01 (45\% vs. 33\%, $p=0,03)$, HLA-DQB1*03:01 (36\% vs. 23,6\%, $p=0,02)$ e HLA-DQB1*04:01 (4\% vs. 1,6\%, $p=0,04)$ em pacientes com PB em comparação com os controles ${ }^{[77]}$. O resultado foi similar ao estudo anterior de Delgado et al. $(1996)^{[74]}$ com caucasianos.

\subsubsection{HLA-DQB1*03:01 e as variantes do penfigoide}

O penfigoide apresenta outras variantes clínicas como o penfigoide das membranas mucosas (PMM), também denominado cicatricial (PC), o penfigoide ocular (PO) e o penfigoide gestacional (PG); e pode manifestar-se sob duas formas clínicas em um mesmo indivíduo. 
Em um estudo americano foi realizada a genotipagem em 21 pacientes com PO (com ou sem comprometimento oral e cutâneo) que mostrou que $76 \%$ desses pacientes carregavam o alelo DQB1*0301(p<0,005), com risco relativo $(\mathrm{RR}) \mathrm{de} 6,4^{[78]}$.

O HLA-DQB1*03:01 parece estar associado a todas as variações clinicas do penfigoide $^{[79]}$. Em um estudo italiano, com um grupo 28 pacientes com o PMM com manifestação oral, o RR associado ao DQB1*0301 foi de $28,7(p=0,001)^{[80]}$. Da mesma maneira, em uma outra pesquisa com 25 pacientes franceses caucasianos, o haplótipo DRB1*1101/ DQB1*0301 revelou-se o mais associado à manifestação oral, à ocular e aos subgrupos cutâneos ${ }^{[81]}$.

\subsection{Genotipagem e o sistema HLA}

A possibilidade de alelos do sistema HLA conferirem risco ou proteção para determinadas doenças, e o não estabelecimento exato dos alelos específicos que estão realmente associados ao $\mathrm{PB}$, demonstram a importância absoluta da genotipagem constante dessas populações. O entendimento real de quais vias estão envolvidas na patogênese pode fornecer um novo planejamento terapêutico, possibilitar maior eficácia e menos efeitos colaterais ${ }^{[82]}$. 


\subsection{A população brasileira}

A população brasileira é uma das mais heterogêneas do mundo, como consequência de cinco séculos de miscigenação entre três raízes ancestrais: os ameríndios autóctones, os europeus e os africanos subsaarianos ${ }^{[83]}$. A maioria dos caucasianos veio de Portugal, Espanha, Itália e Alemanha. Os africanos, trazidos para o Brasil na época colonial, pertencem, em particular, aos grupos de língua Bantu, provenientes da África Equatorial, enquanto os índios se originam predominantemente das tribos Tapuia e Tupi ${ }^{[84]}$.

A população brasileira é, portanto, formada pelo cruzamento dessas três raças, que gera uma população "mestiça", na qual a mistura de caucasianos com índios origina um subtipo denominado "caboclo"; a de caucasianos com africanos determina o subtipo dos "mulatos" e a mistura de africanos com índios forma o subtipo dos “cafuzos". Em razão das diversidades da sua colonização e por ser o território brasileiro muito vasto, as diferentes regiões do país apresentam predominância maior ou menor de cada um dos subtipos populacionais descritos ${ }^{[85]}$.

A heterogeneidade e miscigenação têm implicações importantes em estudos de genotipagem nas mais diversas moléstias existentes. Acrescente-se que na população brasileira ainda não há nenhum estudo referente à associação entre HLA e seus alelos, na manifestação do penfigoide bolhoso e seus subtipos. 
4 CASUÍSTICA E MÉTODO 


\section{CASUÍSTICA E MÉTODO}

\subsection{Casuística}

\subsubsection{Aspectos éticos da pesquisa}

O estudo foi aprovado pelo comitê de ética em pesquisa (CAPPesq) do Hospital das Clínicas da Faculdade de Medicina da USP (HC-FMUSP) - registro on-line 10827, número do parecer 294.201 (Apêndice 1).

Todos os pacientes incluídos no estudo assinaram Termo de Consentimento Livre e Esclarecido (Apêndice 2) e receberam explicação do pesquisador sobre o procedimento e seus objetivos.

\subsubsection{Desenho do estudo}

O desenho do estudo é observacional, do tipo caso-controle.

\subsubsection{Local e população de estudo}

Foram avaliados pacientes com diagnóstico de penfigoide bolhoso (PB), com manifestação de quadro clínico oral, provenientes do Ambulatório de Estomatologia do Hospital das Clínicas da Faculdade de Medicina da Universidade de São Paulo (HC-FMUSP). 


\subsubsection{Critérios de inclusão e exclusão}

\subsubsection{Critérios de inclusão}

Foram incluídos no estudo os pacientes diagnosticados de acordo com os critérios seguintes:

1. Clínico: com história e exame físico de doença bolhosa que envolvesse a mucosa oral e/ou pele;

2. Histopatológico: biópsia de pele e/ou mucosa com sinais de clivagem subepitelial;

3. Imunopatológico: imunofluorescência direta com presença de depósito de IgG e/ou C3, linear, contínuo na ZMB e teste salt-split com coloração no lado epidérmico do material.

\subsubsection{Critérios de exclusão}

Foram excluídos do estudo os pacientes que:

1. Apresentaram diagnóstico de PB e cujo familiar consanguíneo direto já estava participando do estudo.

2. Pacientes que se recusaram a assinar o Termo de Consentimento Livre e Esclarecido (TCLE - Apêndice 2)

\subsubsection{Grupo controle}

Os dados referentes ao grupo controle são constituídos de coletas realizadas na cidade de São Paulo durante o período de 01/01/2011 a 22/03/2012 que foram 
extraídas de 297 doadores de órgãos. As amostras foram tipificadas no Laboratório de Imunologia de Transplantes do InCor para descobrir a compatibilidade do HLA entre os doadores e receptores. Esses dados são armazenados no Sistema Estadual de Transplantes da Secretaria de Saúde do Governo do Estado de São Paulo e contém a idade e a identificação de HLA classe I e II de cada doador.

\subsection{Método}

\subsubsection{Coleta de amostra do sangue periférico}

O trabalho foi dividido em duas etapas. Na primeira, que ocorreu entre setembro de 2013 e fevereiro de 2015, foi realizado o cadastramento de todos os pacientes com diagnóstico de PB do ambulatório de Estomatologia do Hospital das Clínicas e os dados anotados foram: gênero, idade, raça, endereço e telefone para contatos, além da anamnese, revisão de prontuário, história clínica do paciente e confirmação laboratorial do diagnóstico (histopatológico e imunofluorescência).

Na segunda etapa, ocorrida entre março de 2015 e junho de 2015, foi realizada a convocação via telefone dos pacientes e de seus acompanhantes. Após a anamnese, foi colhida uma amostra de $10 \mathrm{~mL}$ de sangue periférico de cada paciente em um tubo contendo $25 \mathrm{mM}$ de EDTA. As amostras foram conservadas em temperatura ambiente e levadas, em até 3 horas, juntamente com o pedido de protocolo de tipagem do HLA (Anexo A), para o laboratório onde foram realizadas as extrações do DNA. 


\subsubsection{Extração e tipificação do DNA}

A extração de DNA e a tipificação HLA da classe II foram realizadas no Laboratório de Imunologia de Transplantes do Instituto do Coração (InCor), conforme protocolo padrão realizado em todos os projetos envolvendo tipagem de HLA descritos nos itens 4.2 .3 e 4.2.4.

\subsubsection{Extração de DNA do sangue pelo método QIAGEN}

A extração de DNA da amostra de sangue periférico foi realizada por meio de kits Qiagen (QIAamp DNA Mini Kit ${ }^{\circledR}$, U.S.A.) mediante os passos seguintes:

- Em um tubo com capacidade de 1,5mL foram adicionados $20 \mu \mathrm{L}$ de proteinase $\mathrm{K}$ e $200 \mu \mathrm{L}$ de buffet coat de sangue fresco ou congelado. O tubo foi colocado em banho-maria a $56^{\circ} \mathrm{C}$ por $3 \mathrm{~h}$, e posteriormente, no vórtex por $5 \mathrm{~s}$. Em seguida, incubado por 10min para promover a quebra das proteínas.

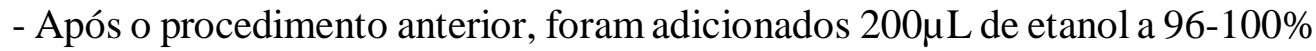
ao lisado e misturados para pipetagem e centrifugação por 1min (Figuras 10 e 11). A seguir, foram adicionados $500 \mu \mathrm{L}$ de Buffer $A W 1$ e a mistura centrifugada novamente por $1 \mathrm{~min}$ em temperatura ambiente. Depois, adicionados $500 \mu \mathrm{L}$ de $B u f f e r A W 2$ e centrifugada a $14.000 \mathrm{rpm}$ por $4 \mathrm{~min}$. Na sequência, foram adicionados $200 \mu \mathrm{L}$ de água destilada e a mistura incubada em temperatura ambiente por 5 min e centrifugada a 8000rpm durante 1min em temperatura ambiente. O DNA foi extraído, purificado, homogeneizado e mantido a $4^{\circ} \mathrm{C}$ para posterior tipificação. 
- Na mesma semana, a concentração de DNA foi medida em espectrofotômetro NanoDrop $^{\mathrm{TM}}$ (ND-1000 UV-VIS, Thermo Fisher Scientific, DE, U.S.A.) (comprimento de onda entre 260nm e 280nm). O valor da razão entre as absorbâncias $260 \mathrm{~nm}$ e $280 \mathrm{~nm}\left(\mathrm{~A}_{260} / \mathrm{A}_{280}\right)$ deveria ser $\geq 1,8$ e $\leq 2,0$. Caso apresentasse valor abaixo de 1,8 , indicaria contaminação com proteínas; e, se acima de 2,0, contaminação com ácido ribonucleico $(\mathrm{RNA})^{[73]}$. Dessa forma, caso estivesse fora do intervalo citado, esse material era descartado, uma nova amostra colhida e feita nova extração de DNA.

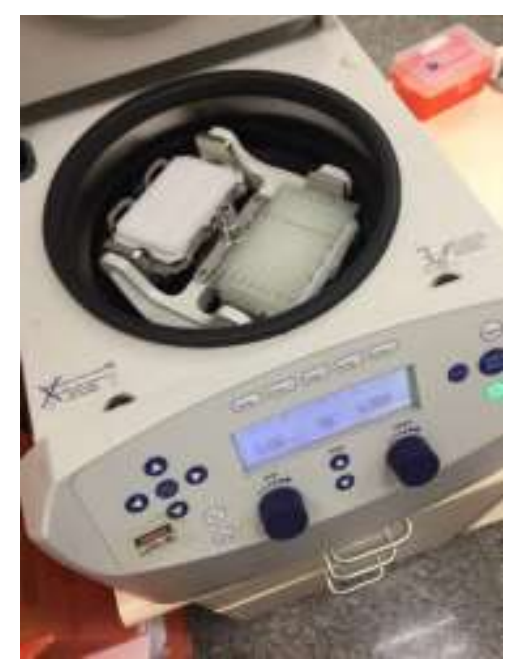

Figura 10. Imagem do equipamento usado para centrifugação das amostras de sangue periférico.

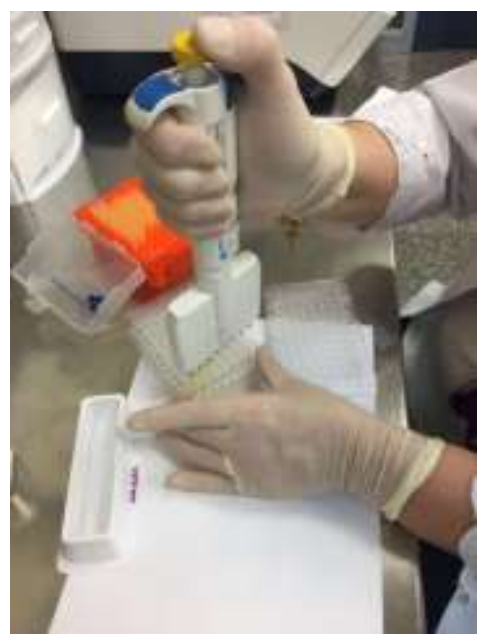

Figura 11. Processo de pipetagem de compostos usados para preparação das amostras de sangue periférico para extração de DNA. 


\subsubsection{Tipificação do HLA pelo método PCR-SSO}

A tipificação do HLA nos loci DR e DQ foi realizada após a extração do DNA utilizando-se a reação em cadeia da polimerase (PCR - do inglês Polymerase Chain Reaction) e amplificação com oligonucleotídeos sequência-específica (SSO - do inglês Sequence-Specific Oligonucleotide $)^{[86,87]}$ por meio de kits LABType ${ }^{\circledR}$ (One Lambda, INC - Canoga Park, CA, U.S.A.). No kit LABType ${ }^{\circledR}$ SSO são utilizadas sondas de oligonucleotídeos sequência específica ligadas às microesferas codificadas por método fluorescente, para identificar alelos correspondentes na amostra de DNA (Anexo B). Com o kit LABType ${ }^{\circledR}$ aplica-se a tecnologia Luminex ${ }^{\circledR}$ para o método de tipificação de DNA SSO reverso. Inicialmente, o DNA alvo é amplificado via PCR, utilizando um iniciador (primer) de grupo específico.

O produto da reação é marcado com biotina, o que permite sua detecção ao utilizar strepavidina conjugada à ficoeritrina-R. Logo após, é desnaturado, permitindo a hibridização das sondas de DNA complementar, conjugadas às microesferas codificadas anteriormente por fluorescência. Um analisador de fluxo, LABScan ${ }^{\mathrm{TM}} 100$ (One Lambda, INC - Canoga Park, CA, U.S.A.; Figura 12), identifica a intensidade de fluorescência da ficoeritrina de cada microesfera. A indicação da tipagem do HLA é baseada no padrão de resultado da reação encontrado e comparado, por meio do programa LABType ${ }^{\mathrm{TM}}$ SSO Analysis Software for Windows, a padrões associados às sequências de genes HLA publicados online ${ }^{[88]}$. 


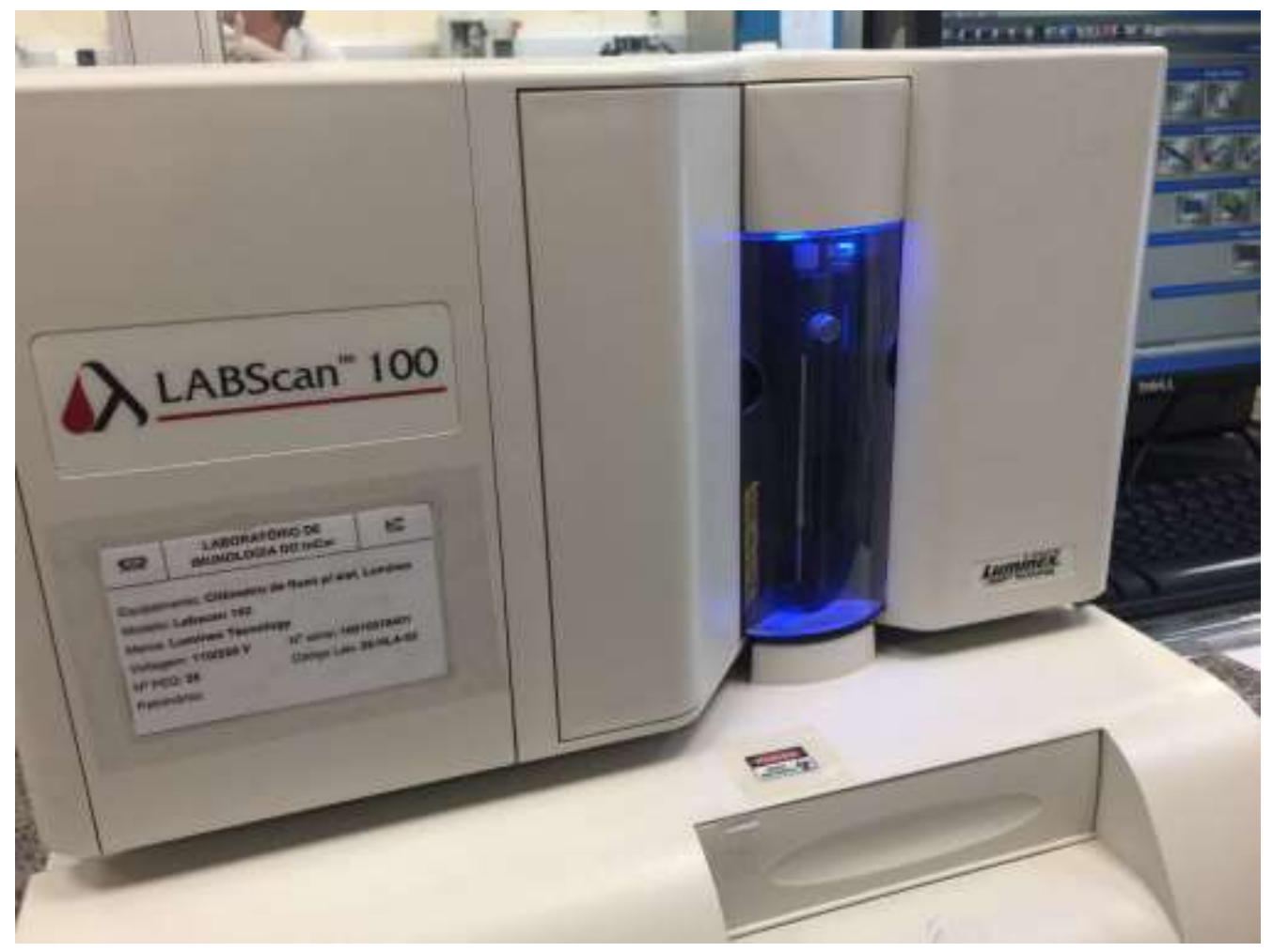

Figura 12. Aparelho LABScan ${ }^{\mathrm{TM}} 100$, utilizado para promover a identificação da tipagem de HLA.

\subsubsection{Análise estatística}

Os dados relacionados com a descrição dos indivíduos com penfigoide bolhoso e os doadores de órgãos (controles) foram armazenados nos softwares estatísticos SPSS for Windows v. $18^{\odot}$ e Stata/SE $11.0^{\odot}$.

A associação entre as variáveis categóricas e os grupos de estudo (penfigoide bolhoso e controles) foram realizadas pelo teste qui-quadrado de Pearson ${ }^{[89]}$. A comparação entre a idade dos participantes foi avaliada pelo teste de Mann-Whitney.

Para o cálculo dos odds ratio (OR) utilizou-se a regressão logística e foram calculados, também, os intervalos com $95 \%$ de confiança para o $\mathrm{OR}^{[90]}$. 
A frequência fenotípica de cada alelo foi apresentada pelo gráfico de barras. Os valores de OR foram apresentados pelo gráfico de forest plot.

O nível de significância adotado foi de 5\% para todos os testes estatísticos, e para o OR foi considerada a correção de Bonferroni ${ }^{[11]}$. 
5 RESULTADOS 


\section{RESULTADOS}

Foram incluídos no estudo 17 pacientes diagnosticados com penfigoide bolhoso (grupo PB) e 297 doadores de órgãos (grupo controle). Além disso, foram tabuladas as informações sobre gênero, raça, idade, naturalidade e fator desencadeante atribuído.

As frequências alélicas do HLA A, B, C, DRB1, DQB1 e DQA1 para os pacientes com PB e controles são apresentadas segundo as frequências e porcentagens, assim como o valor da razão de chances ou odds ratio (OR), com seus respectivos intervalos com $95 \%$ de confiança ( $\left.\mathrm{IC}_{95 \%}\right)$.

Os valores do OR são apresentados para cada uma das frequências alélicas no formato de forest plot como apresentado para estudos de metanálise com o objetivo de melhor visualização.

Os pacientes com PB e os doadores de órgãos (controles), segundo gênero, cor e idade são apresentados na Tabela 1, e o estado de origem no Gráfico 1. 
Tabela 1. Características dos pacientes com penfigoide bolhoso e dos doadores de órgãos (controles), HC-FMUSP, 2016.

\begin{tabular}{ll|c|c|c|c}
\hline \multicolumn{2}{l|}{ Característica } & $\begin{array}{c}\text { Penfigoide } \\
\text { bolhoso }\end{array}$ & Controles & \multirow{2}{*}{ Total } & $\begin{array}{c}\text { Valor } \\
\text { de } \boldsymbol{p}\end{array}$ \\
\cline { 3 - 4 } Gênero & Masculino, $\mathrm{n}(\%)$ & $8(47,1)$ & $183(61,6)$ & 191 & $0,232^{1}$ \\
& Feminino, $\mathrm{n}(\%)$ & $9(52,9)$ & $114(38,4)$ & 123 & \\
Cor & Branca, $\mathrm{n}(\%)$ & $10(58,8)$ & $\mathrm{NA}$ & 10 & $\mathrm{NA}$ \\
& Negra, $\mathrm{n}(\%)$ & $1(5,9)$ & $\mathrm{NA}$ & 1 & \\
& Pardo, n (\%) & $6(35,3)$ & $\mathrm{NA}$ & 6 & \\
\multirow{2}{*}{$\begin{array}{l}\text { Idade } \\
\text { (anos) }\end{array}$} & Média (DP) & $63,71(20,71)$ & $43,03(17,55)$ & $44,15(18,30)$ & $<0,001^{2}$ \\
& $\begin{array}{l}\text { Mediana } \\
\text { (min-máx) }\end{array}$ & $69(26-88)$ & $46(1-74)$ & $47(1-88)$ & \\
\hline
\end{tabular}

n: quantidade de indivíduos; \%: por cento; NA: não avaliável; DP: desvio padrão; min: valor mínimo; máx: valor máximo. ${ }^{1}$ Teste de associação qui-quadrado de Pearson; ${ }^{2}$ Teste não-paramétrico Mann-Whitney.

Gráfico 1. Distribuição dos casos de penfigoide bolhoso incluídos no estudo segundo o Estado de origem.

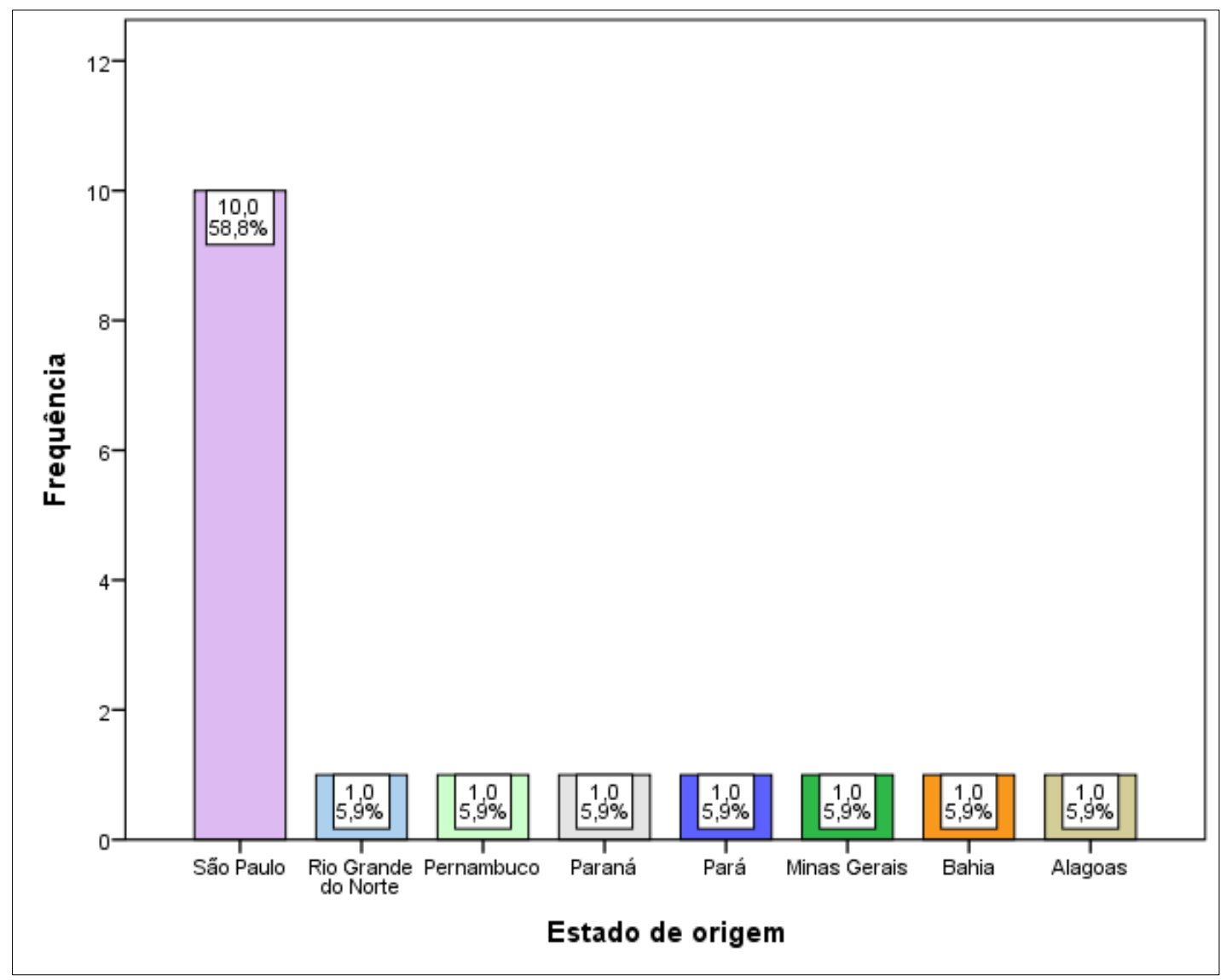


Pouco mais da metade dos casos com penfigoide bolhoso eram do gênero feminino $(52,9 \%)$ e aproximadamente $62 \%$ dos doadores de órgãos (controles) eram do gênero masculino. No entanto, não se encontrou associação estatisticamente significativa entre o gênero e os grupos PB e controle $(p=0,232)$. Mas, foram observadas diferenças estatisticamente significativas na distribuição das idades entre os grupos $(p<0,001)$.

A maior parte dos pacientes estudados, nasceu no Estado de São Paulo $(58,8 \%)$, porém com participação de outros sete Estados brasileiros. Não houve informação disponível da cor da pele para os doadores de órgãos.

Foram coletadas informações, com auxílio de um questionário, sobre os possíveis fatores desencadeantes do penfigoide bolhoso e os resultados estão no Gráfico 2. 
Gráfico 2. Distribuição dos casos de penfigoide bolhoso segundo fator desencadeante.

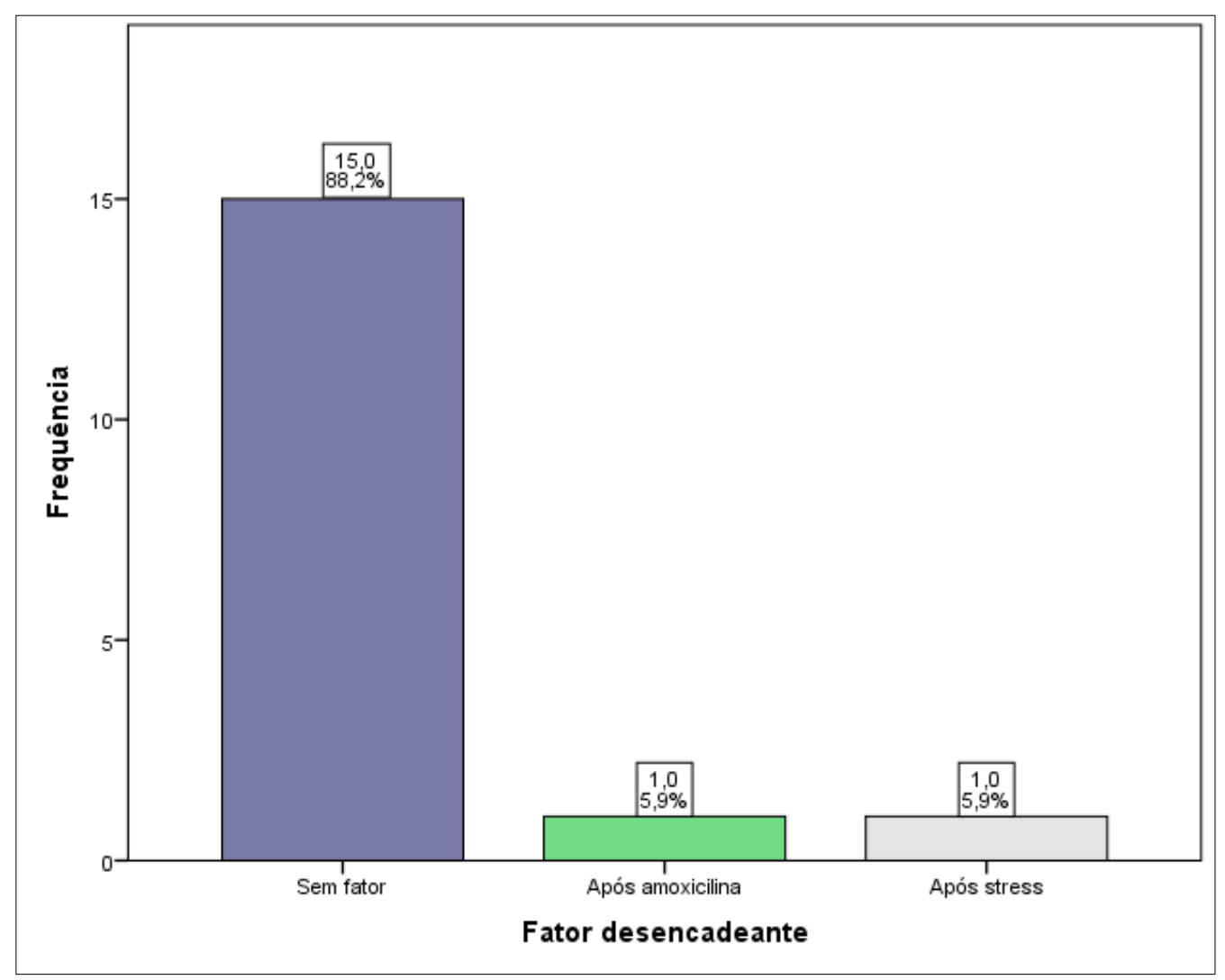

A Tabela 2 mostra a prevalência fenotípica dos alelos do HLA A para os pacientes com penfigoide bolhoso e os doadores de órgãos (controles). 
Tabela 2. Prevalência fenotípica dos alelos do HLA A para os pacientes com penfigoide bolhoso e os doadores de órgãos (controles), HC-FMUSP, 2016.

\begin{tabular}{|c|c|c|c|c|}
\hline \multirow{3}{*}{ HLA A } & $\begin{array}{c}\text { Penfigoide } \\
\text { bolhoso }\end{array}$ & Controles & \multirow{3}{*}{$\mathrm{OR}\left(\mathrm{IC}_{95 \%}\right)$} & \multirow{3}{*}{ Valor de $p^{1 \S}$} \\
\hline & $\mathrm{n}=34$ & $\mathrm{n}=594$ & & \\
\hline & $\mathrm{n}(\%)$ & $\mathrm{n}(\%)$ & & \\
\hline$A * 01$ & $5(14,7)$ & $53(8,9)$ & $1,76(0,65-4,74)$ & 0,263 \\
\hline$A * 02$ & $10(29,4)$ & $136(22,9)$ & $1,40(0,66-3,01)$ & 0,384 \\
\hline$A * 03$ & $4(11,8)$ & $50(8,4)$ & $1,45(0,49-4,28)$ & 0,501 \\
\hline$A * 11$ & $1(2,9)$ & $36(6,1)$ & $0,47(0,06-3,53)$ & 0,463 \\
\hline$A * 23$ & $3(8,8)$ & $39(6,6)$ & $1,38(0,40-4,71)$ & 0,610 \\
\hline$A * 24$ & $1(2,9)$ & $59(9,9)$ & $0,28(0,04-2,05)$ & 0,207 \\
\hline$A * 25$ & 0 & $12(2,0)$ & NA & NA \\
\hline$A * 26$ & $2(5,9)$ & $16(2,7)$ & $2,26(0,50-10,25)$ & 0,291 \\
\hline$A * 29$ & $1(2,9)$ & $30(5,1)$ & $0,57(0,08-4,31)$ & 0,586 \\
\hline$A * 30$ & $3(8,8)$ & $38(6,4)$ & $1,42(0,41-4,84)$ & 0,579 \\
\hline$A * 31$ & $1(2,9)$ & $26(4,4)$ & $0,66(0,09-5,03)$ & 0,690 \\
\hline$A * 32$ & $1(2,9)$ & $15(2,5)$ & $1,17(0,15-9,13)$ & 0,881 \\
\hline$A * 33$ & $1(2,9)$ & $27(4,5)$ & $0,64(0,08-4,83)$ & 0,662 \\
\hline$A * 34$ & $1(2,9)$ & $4(0,7)$ & $4,47(0,49-41,12)$ & 0,186 \\
\hline$A * 36$ & 0 & $2(0,3)$ & NA & NA \\
\hline$A * 66$ & 0 & $4(0,7)$ & NA & NA \\
\hline$A * 68$ & 0 & $33(5,6)$ & NA & NA \\
\hline$A * 69$ & 0 & $1(0,2)$ & NA & NA \\
\hline$A * 74$ & 0 & $13(2,2)$ & NA & NA \\
\hline
\end{tabular}

n: quantidade de indivíduos; OR (IC95\%): Odds ratio (intervalo de confiança de 95\%); NA: não avaliável. ${ }^{1}$ Valor de $p$ para OR utilizando a regressão logística. ${ }^{\S}$ Nível de significância com correção de Bonferroni para $\alpha=0,05$ : $\alpha / 19=0,05 / 19=0,003$.

Não se encontrou associação significativa entre os valores de OR das frequências fenotípicas do HLA A como observado na Tabela 2.

O Gráfico 3 mostra o valor de Odds ratio (OR) dos alelos do HLA A para os pacientes com penfigoide bolhoso e os doadores de órgãos (controles). 
Gráfico 3. Odds ratio (OR) dos alelos do HLA A para os pacientes com penfigoide bolhoso e os doadores de órgãos (controles), HC-FMUSP, 2016.

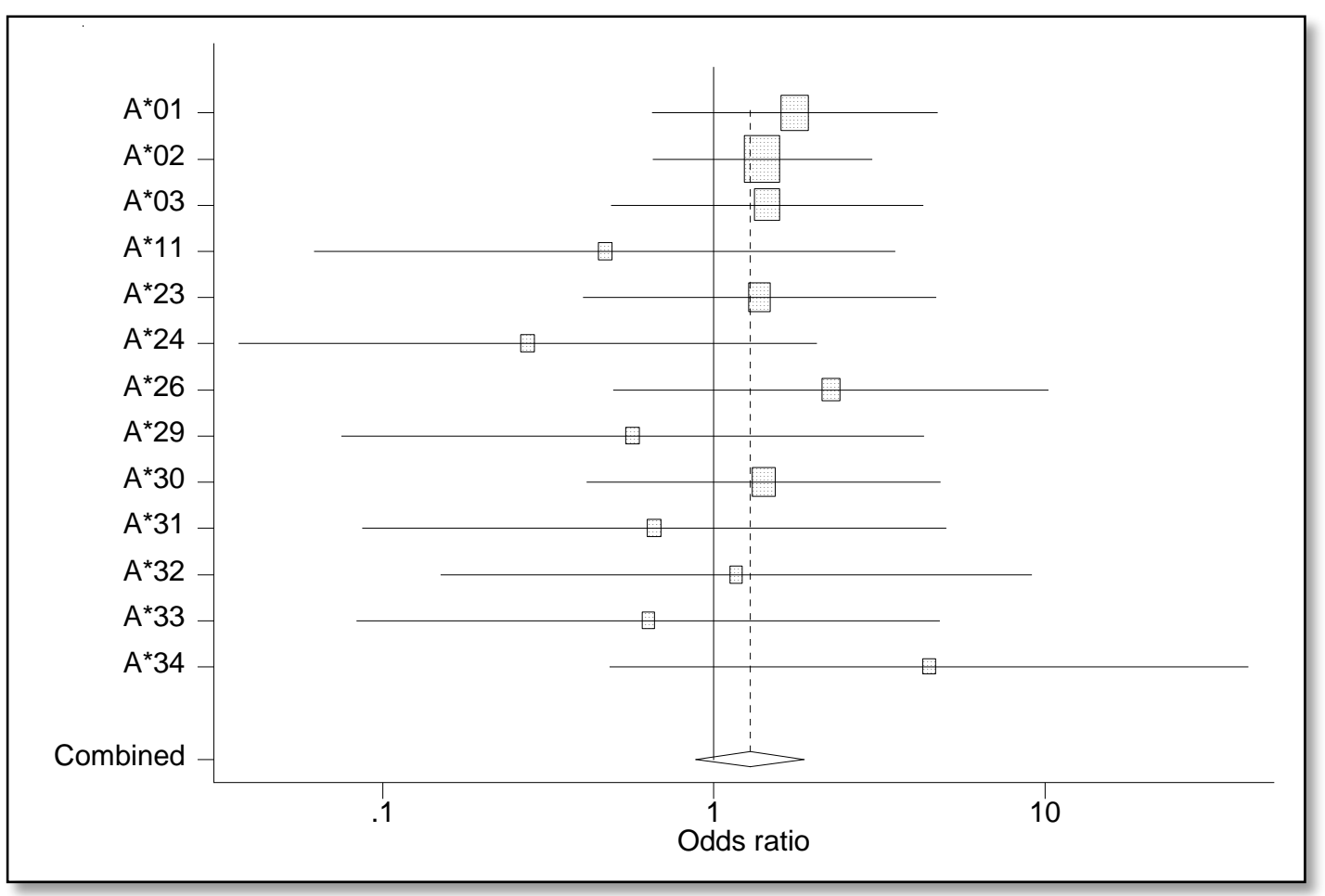

A Tabela 3 mostra a prevalência fenotípica dos alelos do HLA B para os pacientes com penfigoide bolhoso e os doadores de órgãos (controles). 
Tabela 3. Prevalência fenotípica dos alelos do HLA B para os pacientes com penfigoide bolhoso e os doadores de órgãos (controles), HC-FMUSP, 2016.

\begin{tabular}{|c|c|c|c|c|}
\hline \multirow{3}{*}{ HLA B } & $\begin{array}{c}\text { Penfigoide } \\
\text { bolhoso }\end{array}$ & Controles & \multirow{3}{*}{ OR $\left(\mathrm{IC}_{95 \%}\right)$} & \multirow{3}{*}{ Valor de $p^{1 \S}$} \\
\hline & $\mathrm{n}=34$ & $\mathrm{n}=594$ & & \\
\hline & $\mathrm{n}(\%)$ & $\mathrm{n}(\%)$ & & \\
\hline B*07 & $3(8,8)$ & $32(5,4)$ & $1,70(0,49-5,86)$ & 0,401 \\
\hline B*08 & 0 & $26(4,4)$ & NA & NA \\
\hline B*13 & 0 & $12(2,0)$ & NA & NA \\
\hline B*14 & $1(2,9)$ & $38(6,4)$ & $0,44(0,06-3,33)$ & 0,429 \\
\hline $\mathrm{B} * 15$ & $1(2,9)$ & $63(10,6)$ & $0,26(0,03-1,90)$ & 0,182 \\
\hline B*18 & $1(2,9)$ & $32(5,4)$ & $0,53(0,07-4,02)$ & 0,541 \\
\hline $\mathrm{B} * 27$ & 0 & $11(1,9)$ & NA & NA \\
\hline $\mathrm{B} * 35$ & $4(11,8)$ & $74(12,5)$ & $0,94(0,32-2,74)$ & 0,905 \\
\hline $\mathrm{B} * 37$ & $1(2,9)$ & $8(1,3)$ & $2,22(0,27-18,28)$ & 0,459 \\
\hline B*38 & $2(5,9)$ & $9(1,5)$ & $4,06(0,84-19,59)$ & 0,081 \\
\hline B*39 & $1(2,9)$ & $19(3,2)$ & $0,92(0,12-7,06)$ & 0,934 \\
\hline$B * 40$ & $2(5,9)$ & $31(5,2)$ & $1,14(0,26-4,96)$ & 0,866 \\
\hline$B * 41$ & $2(5,9)$ & $8(1,3)$ & $4,58(0,93-22,45)$ & 0,061 \\
\hline$B * 42$ & $2(5,9)$ & $5(0,8)$ & $7,36(1,38-39,42)$ & 0,020 \\
\hline$B * 44$ & $8(23,5)$ & $57(9,6)$ & $2,90(1,25-6,70)$ & 0,013 \\
\hline$B * 45$ & 0 & $11(1,9)$ & NA & NA \\
\hline$B * 47$ & 0 & $4(0,7)$ & NA & NA \\
\hline$B * 48$ & 0 & $2(0,3)$ & NA & NA \\
\hline$B * 49$ & $2(5,9)$ & $16(2,7)$ & $2,26(0,50-10,25)$ & 0,291 \\
\hline$B * 50$ & $1(2,9)$ & $15(2,5)$ & $1,17(0,15-9,13)$ & 0,881 \\
\hline $\mathrm{B} * 51$ & $1(2,9)$ & $48(8,1)$ & $0,35(0,05-2,58)$ & 0,299 \\
\hline$B * 52$ & $1(2,9)$ & $8(1,3)$ & $2,22(0,27-18,28)$ & 0,459 \\
\hline $\mathrm{B} * 53$ & 0 & $15(2,5)$ & NA & NA \\
\hline$B * 54$ & 0 & $1(0,2)$ & NA & NA \\
\hline$B * 55$ & 0 & $7(1,2)$ & NA & NA \\
\hline $\mathrm{B} * 57$ & 0 & $20(3,4)$ & NA & NA \\
\hline $\mathrm{B} * 58$ & $1(2,9)$ & $16(2,7)$ & $1,10(0,14-8,51)$ & 0,931 \\
\hline $\mathrm{B} * 73$ & 0 & $1(0,2)$ & NA & NA \\
\hline $\mathrm{B} * 81$ & 0 & $5(0,8)$ & NA & NA \\
\hline
\end{tabular}

n: quantidade de indivíduos; OR (IC95\%): Odds ratio (intervalo de confiança de 95\%); NA: não avaliável. ${ }^{1}$ Valor de $p$ para OR utilizando a regressão logística. ${ }^{\S}$ Nível de significância com correção de Bonferroni para $\alpha=0,05$ : $\alpha / 29=0,05 / 29=0,002$. 
Na Tabela 3 também não houve diferenças nas razões de chance das frequências fenotípicas do HLA B entre pacientes com penfigoide bolhoso e doadores (controles). No Gráfico 4 podem ser vistos os valores de Odds ratio (OR) dos alelos do HLA B para os dois grupos.

Gráfico 4. Odds ratio (OR) dos alelos do HLA B para os pacientes com penfigoide bolhoso e os doadores de órgãos (controles), HC-FMUSP, 2016.

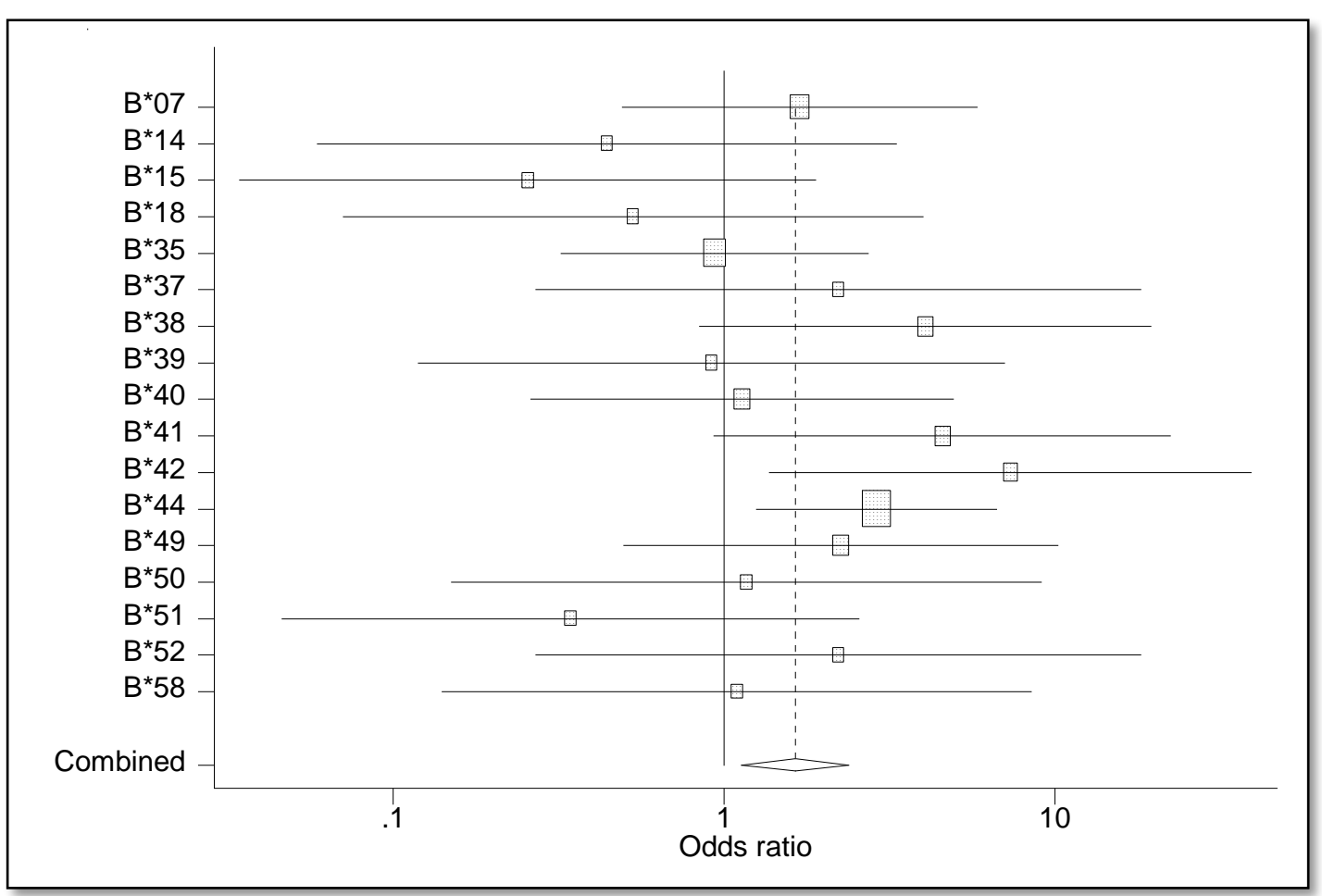

A Tabela 4 mostra os dados da prevalência fenotípica dos alelos do HLA C para os pacientes com penfigoide bolhoso e os doadores de órgãos (controles). 
Tabela 4. Prevalência fenotípica dos alelos do HLA C para os pacientes com penfigoide bolhoso e os doadores de órgãos (controles), HCFMUSP, 2016.

\begin{tabular}{|c|c|c|c|c|}
\hline \multirow{3}{*}{ HLA C } & $\begin{array}{c}\text { Penfigoide } \\
\text { bolhoso }\end{array}$ & Controles & \multirow{3}{*}{ OR $\left(\mathrm{IC}_{95 \%}\right)$} & \multirow{3}{*}{ Valor de $p^{1}$} \\
\hline & $\mathrm{n}=34$ & $\mathrm{n}=592$ & & \\
\hline & $\mathrm{n}(\%)$ & $\mathrm{n}(\%)$ & & \\
\hline $\mathrm{C}^{*} 01$ & 0 & $14(2,4)$ & NA & NA \\
\hline $\mathrm{C}^{*} 02$ & $1(3,1)$ & $33(5,6)$ & $0,55(0,07-4,13)$ & 0,558 \\
\hline$C * 03$ & $2(6,3)$ & $70(11,8)$ & $0,50(0,12-2,13)$ & 0,346 \\
\hline$C^{*} 04$ & $4(12,5)$ & $99(16,7)$ & $0,71(0,24-2,07)$ & 0,533 \\
\hline $\mathrm{C}^{*} 05$ & $5(15,6)$ & $31(5,2)$ & $3,35(1,21-9,30)$ & 0,020 \\
\hline $\mathrm{C}^{*} 06$ & $2(6,3)$ & $60(10,1)$ & $0,59(0,14-2,54)$ & 0,479 \\
\hline $\mathrm{C}^{*} 07$ & $9(28,1)$ & $111(18,8)$ & $1,70(0,76-3,77)$ & 0,195 \\
\hline $\mathrm{C}^{*} 08$ & $1(3,1)$ & $44(7,4)$ & $0,40(0,05-3,01)$ & 0,375 \\
\hline$C^{*} 12$ & $4(12,5)$ & $37(6,3)$ & $2,14(0,71-6,43)$ & 0,174 \\
\hline$C^{*} 14$ & 0 & $20(3,4)$ & NA & NA \\
\hline$C^{*} 15$ & 0 & $26(4,4)$ & NA & NA \\
\hline$C^{*} 16$ & 0 & $29(4,9)$ & NA & NA \\
\hline$C^{* 17}$ & $4(12,5)$ & $10(1,7)$ & $8,31(2,46-28,16)$ & $0,001^{*}$ \\
\hline$C^{*} 18$ & 0 & $8(1,4)$ & NA & NA \\
\hline
\end{tabular}

n: quantidade de indivíduos; OR (IC95\%): Odds ratio (intervalo de confiança de 95\%); NA: não avaliável. ${ }^{1}$ Valor de $p$ para OR utilizando a regressão logística. ${ }^{\S}$ Nível de significância com correção de Bonferroni para $\alpha=0,05$ : $\alpha / 14=0,05 / 14=0,004 .{ }^{*}$ significativo $p<0,0035714$.

Indivíduos com HLA C*17 tem chance aproximadamente oito vezes maior de apresentar penfigoide bolhoso quando comparada com pessoas que não tem esse fenótipo $(p<0,001)$. Outras frequências fenotípicas do HLA C não apresentaram associação com penfigoide (Tabela 4).

O Gráfico 5 exibe os valores de Odds ratio (OR) dos alelos do HLA C para os pacientes com penfigoide bolhoso e os doadores de órgãos (controles). 
Gráfico 5. Odds ratio (OR) dos alelos do HLA C para os pacientes com penfigoide bolhoso e os doadores de órgãos (controles), HC-FMUSP, 2016.

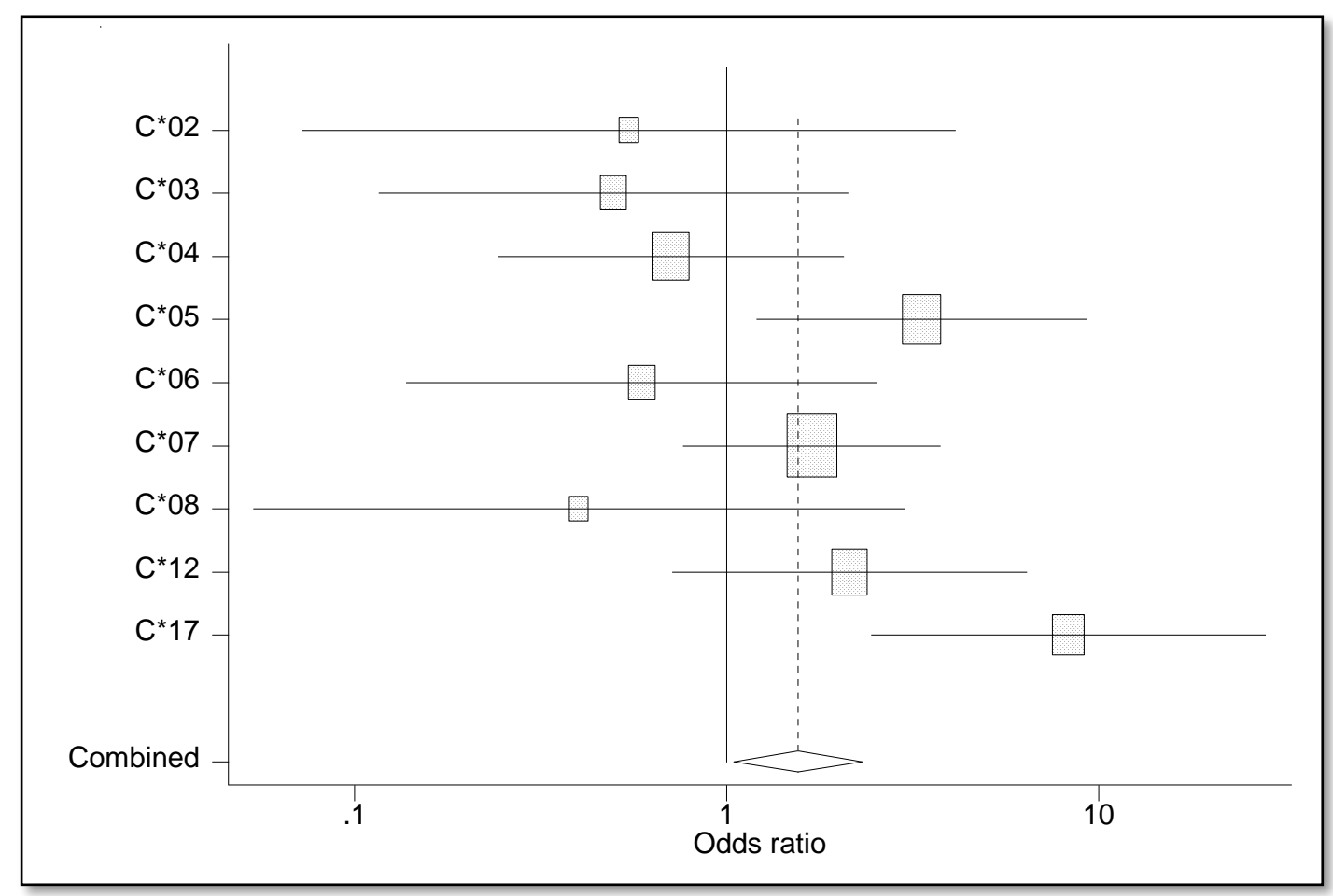

A Tabela 5 mostra a prevalência fenotípica dos alelos do HLA DRB1 para os pacientes com penfigoide bolhoso e os doadores de órgãos (controles). 
Tabela 5. Prevalência fenotípica dos alelos do HLA DRB1 para os pacientes com penfigoide bolhoso e os doadores de órgãos (controles), HC-FMUSP, 2016.

\begin{tabular}{|c|c|c|c|c|}
\hline \multirow{3}{*}{ HLA DRB1 } & $\begin{array}{c}\text { Penfigoide } \\
\text { bolhoso }\end{array}$ & Controles & \multirow{3}{*}{ OR $\left(\mathrm{IC}_{95 \%}\right)$} & \multirow{3}{*}{ Valor de $p^{1 \S}$} \\
\hline & $\mathrm{n}=34$ & $n=594$ & & \\
\hline & $\mathrm{n}(\%)$ & $\mathrm{n}(\%)$ & & \\
\hline $\mathrm{DRB} 1 * 01$ & $3(8,8)$ & $61(10,3)$ & $0,85(0,25-2,85)$ & 0,787 \\
\hline $\mathrm{DRB} 1 * 03$ & $3(8,8)$ & $66(11,1)$ & $0,77(0,23-2,60)$ & 0,679 \\
\hline DRB $1 * 04$ & $2(5,9)$ & $66(11,1)$ & $0,50(0,12-2,13)$ & 0,349 \\
\hline DRB $1 * 07$ & $1(2,9)$ & $80(13,5)$ & $0,20(0,03-1,44)$ & 0,109 \\
\hline DRB $1 * 08$ & $1(2,9)$ & $40(6,7)$ & $0,42(0,06-3,15)$ & 0,398 \\
\hline DRB1*09 & $1(2,9)$ & $9(1,5)$ & $1,97(0,24-16,01)$ & 0,526 \\
\hline DRB $1 * 10$ & $1(2,9)$ & $13(2,2)$ & $1,35(0,17-10,67)$ & 0,773 \\
\hline DRB $1 * 11$ & $8(23,5)$ & $52(8,8)$ & $3,21(1,38-7,44)$ & 0,007 \\
\hline $\mathrm{DRB} 1 * 12$ & $1(2,9)$ & $16(2,7)$ & $1,10(0,14-8,51)$ & 0,931 \\
\hline $\mathrm{DRB} 1 * 13$ & $7(20,6)$ & $81(13,6)$ & $1,64(0,69-3,90)$ & 0,260 \\
\hline $\mathrm{DRB} 1 * 14$ & 0 & $30(5,1)$ & NA & NA \\
\hline DRB1*15 & $4(11,8)$ & $61(10,3)$ & $1,17(0,40-3,42)$ & 0,781 \\
\hline DRB1*16 & $2(5,9)$ & $19(3,2)$ & $1,89(0,42-8,48)$ & 0,405 \\
\hline
\end{tabular}

Não se observou associação entre as frequências fenotípicas do HLA DRB1 com o penfigoide bolhoso na Tabela 5 .

O Gráfico 6 exibe os valores de Odds ratio (OR) dos alelos do HLA DRB1 para os pacientes com penfigoide bolhoso e os doadores de órgãos (controles). 
Gráfico 6. Odds ratio (OR) dos alelos do HLA DRB1 para os pacientes com penfigoide bolhoso e os doadores de órgãos (controles), HCFMUSP, 2016.

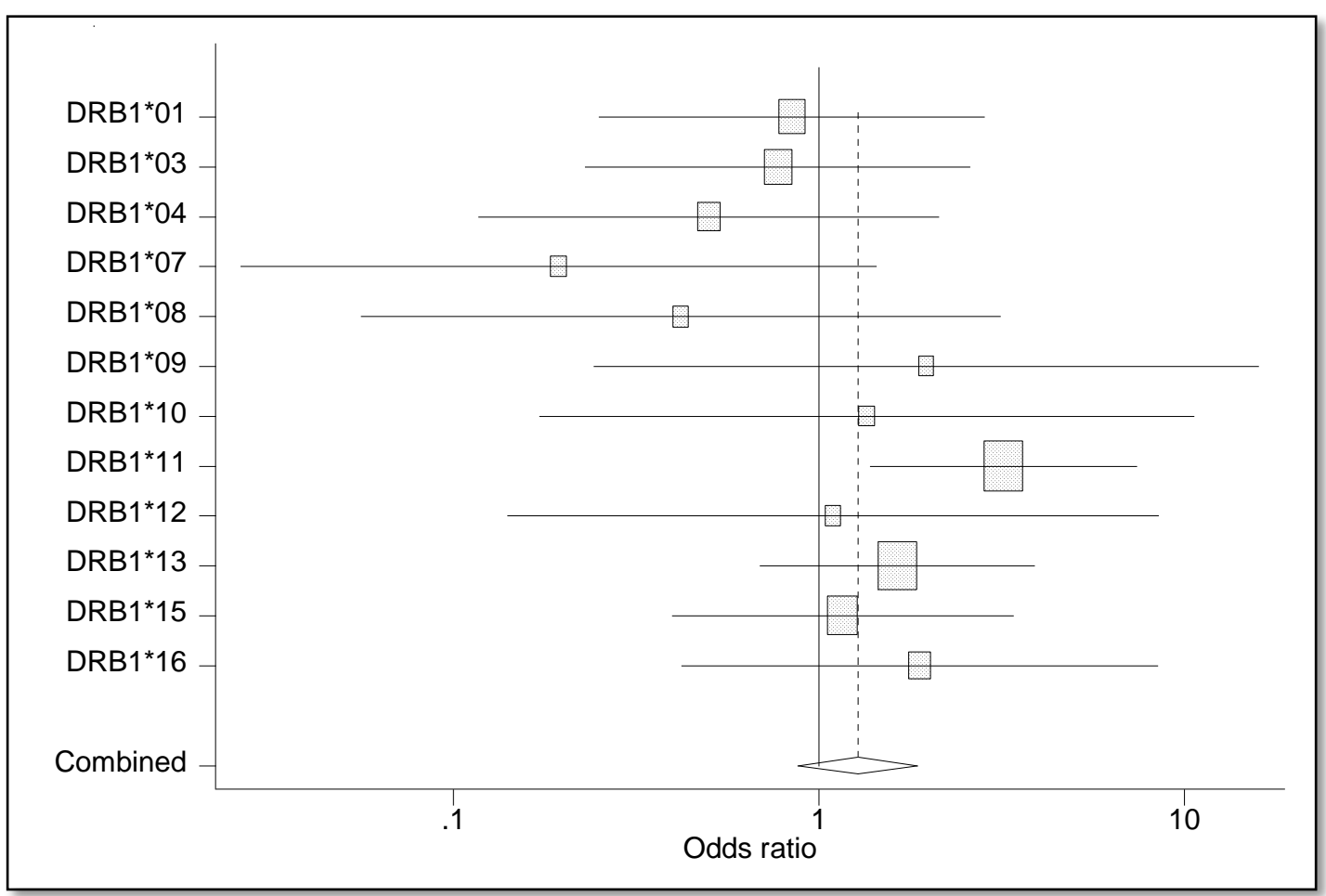

A Tabela 6 apresenta a prevalência fenotípica dos alelos do HLA DQB1 alta definição para os pacientes com penfigoide bolhoso e os doadores de órgãos (controles). 
Tabela 6. Prevalência fenotípica dos alelos do HLA DQB1 alta definição para os pacientes com penfigoide bolhoso e os doadores de órgãos (controles), HC-FMUSP, 2016.

\begin{tabular}{|c|c|c|c|c|}
\hline \multirow{3}{*}{ HLA DQB1 } & $\begin{array}{c}\text { Penfigoide } \\
\text { bolhoso }\end{array}$ & Controles & \multirow{3}{*}{ OR $\left(\mathrm{IC}_{95 \%}\right)$} & \multirow{3}{*}{ Valor de $p^{1 \S}$} \\
\hline & $\mathrm{n}=34$ & $\mathrm{n}=594$ & & \\
\hline & $\mathrm{n}(\%)$ & $\mathrm{n}(\%)$ & & \\
\hline DQB1*02:01 & 0 & $59(9,9)$ & NA & NA \\
\hline DQB1*02:02 & $2(5,9)$ & $74(12,5)$ & $0,44(0,10-1,87)$ & 0,266 \\
\hline DQB1*02:03 & 0 & $1(0,2)$ & NA & NA \\
\hline DQB1*03:01 & $13(38,2)$ & $84(14,1)$ & $3,76(1,81-7,79)$ & $0,000372^{* *}$ \\
\hline DQB1*03:02 & $1(2,9)$ & $52(8,8)$ & $0,32(0,04-2,36)$ & 0,261 \\
\hline DQB1*03:03 & $1(2,9)$ & $9(1,5)$ & $1,97(0,24-16,01)$ & 0,526 \\
\hline DQB1*03:04 & 0 & $1(0,2)$ & NA & NA \\
\hline DQB1*03:19 & 0 & $13(2,2)$ & NA & NA \\
\hline DQB1*04:01 & 0 & $2(0,3)$ & NA & NA \\
\hline DQB1*04:02 & $4(11,8)$ & $42(7,1)$ & $1,75(0,59-5,21)$ & 0,313 \\
\hline DQB1*04:04 & 0 & $2(0,3)$ & NA & NA \\
\hline DQB1*05:01 & $3(8,8)$ & $83(14,0)$ & $0,60(0,18-1,99)$ & 0,401 \\
\hline DQB1*05:02 & $1(2,9)$ & $18(3,0)$ & $0,97(0,13-7,49)$ & 0,976 \\
\hline DQB1*05:03 & 0 & $21(3,5)$ & NA & NA \\
\hline DQB1*05:07 & 0 & $2(0,3)$ & NA & NA \\
\hline DQB1*06:01 & 0 & $5(0,8)$ & NA & NA \\
\hline DQB1*06:02 & $5(14,7)$ & $59(9,9)$ & $1,56(0,58-4,19)$ & 0,375 \\
\hline DQB1*06:03 & $3(8,8)$ & $38(6,4)$ & $1,42(0,41-4,84)$ & 0,579 \\
\hline DQB1*06:04 & $1(2,9)$ & $18(3,0)$ & $0,97(013-7,49)$ & 0,976 \\
\hline DQB1*06:05 & 0 & $1(0,2)$ & NA & NA \\
\hline DQB1*06:08 & 0 & $1(0,2)$ & NA & NA \\
\hline DQB1*06:09 & 0 & $3(0,5)$ & NA & NA \\
\hline DQB1*06:11 & 0 & $4(0,7)$ & NA & NA \\
\hline DQB1*06:19 & 0 & $1(0,2)$ & NA & NA \\
\hline DQB1*06:27 & 0 & $1(0,2)$ & NA & NA \\
\hline
\end{tabular}


Indivíduos com o HLA DQB1*03:01 têm chance 3,8 vezes maior de apresentar penfigoide bolhoso comparado com pessoas que não apresentam esse alelo.

O Gráfico 7 mostra o Odds ratio (OR) dos alelos do HLA DQB1 alta definição para os pacientes com penfigoide bolhoso e os doadores de órgãos (controles).

Gráfico 7. Odds ratio (OR) dos alelos do HLA DQB1 alta definição para os pacientes com penfigoide bolhoso e os doadores de órgãos (controles), HC-FMUSP, 2016.

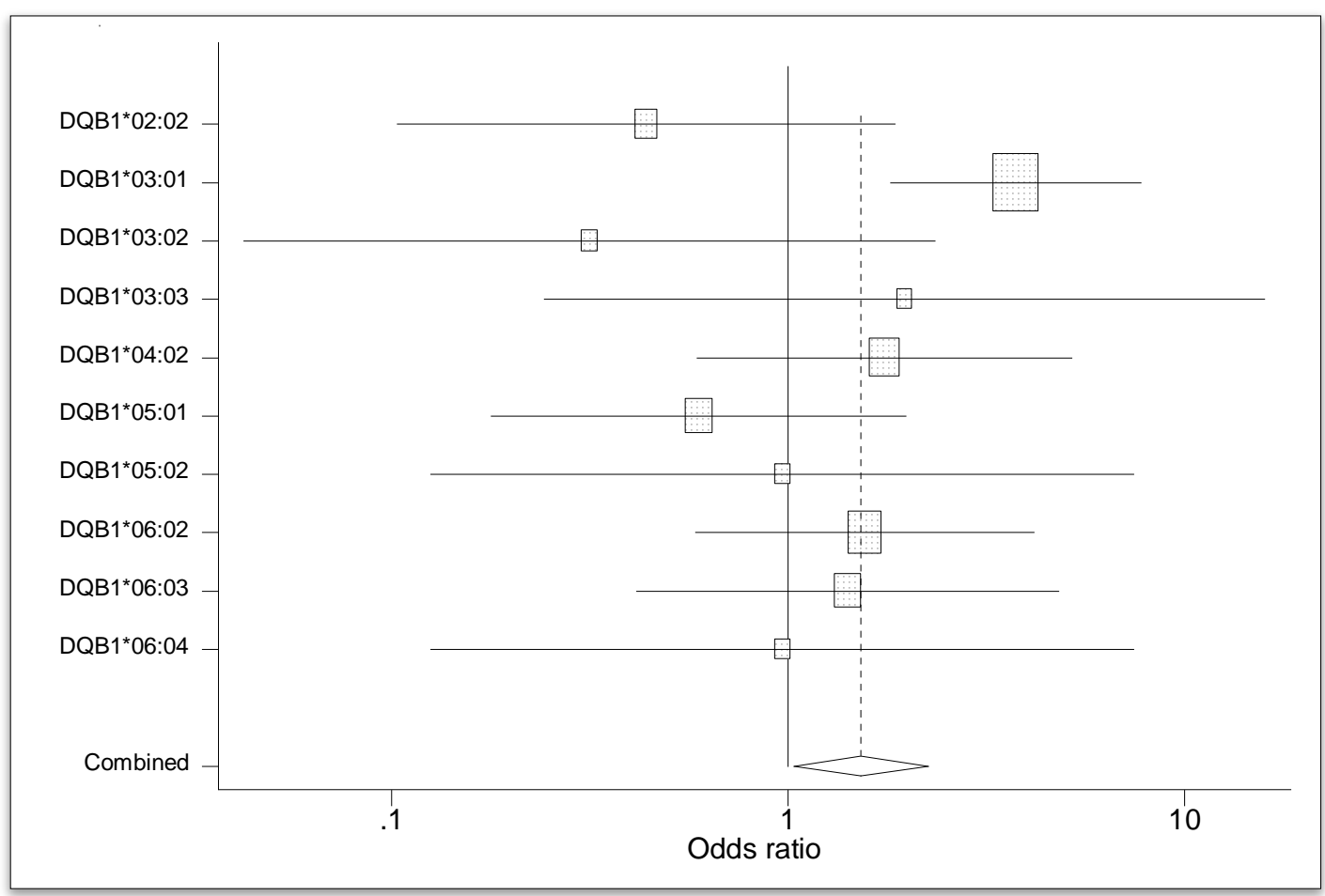

A Tabela 7 exibe os dados de prevalência fenotípica dos alelos do HLA DQA1 alta definição para os pacientes com penfigoide bolhoso e os doadores de órgãos (controles). 
Tabela 7. Prevalência fenotípica dos alelos do HLA DQA1 alta definição para os pacientes com penfigoide bolhoso e os doadores de órgãos (controles), HC-FMUSP, 2016.

\begin{tabular}{|c|c|c|c|c|}
\hline \multirow{3}{*}{ HLA DQA1 } & $\begin{array}{c}\text { Penfigoide } \\
\text { bolhoso }\end{array}$ & Controles & \multirow{3}{*}{ OR $\left(\mathrm{IC}_{95 \%}\right)$} & \multirow{3}{*}{ Valor de $p^{1 \S}$} \\
\hline & $\mathrm{n}=34$ & $\mathrm{n}=594$ & & \\
\hline & $\mathrm{n}(\%)$ & $\mathrm{n}(\%)$ & & \\
\hline DQA1*01:01 & $3(8,8)$ & $80(13,5)$ & $0,62(0,19-2,08)$ & 0,439 \\
\hline DQA1*01:02 & $2(5,9)$ & $127(21,4)$ & $0,23(0,05-0,97)$ & 0,045 \\
\hline DQA1*01:03 & $8(23,5)$ & $47(7,9)$ & $3,57(1,53-8,33)$ & $0,003^{* *}$ \\
\hline DQA1*02:01 & $1(2,9)$ & $74(12,5)$ & $0,21(0,03-1,58)$ & 0,130 \\
\hline DQA1*03:01 & $3(8,8)$ & $59(9,9)$ & $0,88(0,26-2,95)$ & 0,831 \\
\hline DQA1*03:02 & $1(2,9)$ & $20(3,4)$ & $0,87(0,11-6,67)$ & 0,892 \\
\hline DQA1*04:01 & $3(8,8)$ & $40(6,7)$ & $1,34(0,39-4,57)$ & 0,642 \\
\hline DQA1*04:02 & 0 & $1(0,2)$ & NA & NA \\
\hline DQA1*05:01 & 0 & $68(11,4)$ & NA & NA \\
\hline DQA1*05:03 & $2(5,9)$ & $10(1,7)$ & $3,64(0,77-17,33)$ & 0,104 \\
\hline DQA1*05:05 & $11(32,4)$ & $64(10,8)$ & $4,02(1,87-8,64)$ & $0,000358^{* *}$ \\
\hline DQA1*06:01 & 0 & $3(0,5)$ & NA & NA \\
\hline
\end{tabular}

Indivíduos com o alelo DQA1*01:03 e DQA1*05:05 presente têm aproximadamente 3,6 e 4 vezes, respectivamente, chances maiores de terem penfigoide bolhoso quando comparados com indivíduos que não apresentam esses alelos (Tabela 7).

O Gráfico 8 exibe os valores de Odds ratio (OR) dos alelos do HLA DQA1 alta definição para os pacientes com penfigoide bolhoso e os doadores de órgãos (controles). 
Gráfico 8. Odds ratio (OR) dos alelos do HLA DQA1 alta definição para os pacientes com penfigoide bolhoso e os doadores de órgãos (controles), HC-FMUSP, 2016.

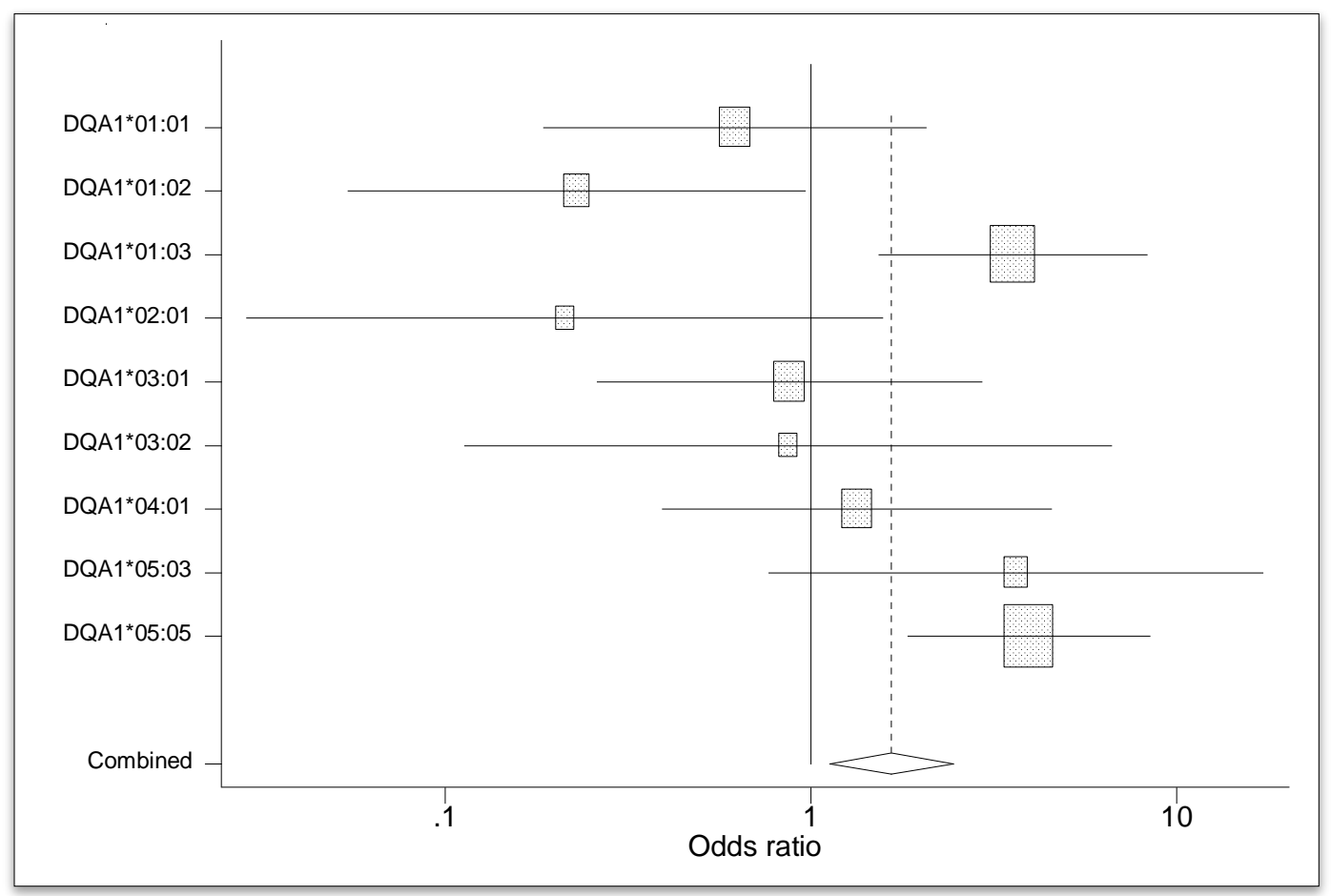


6 DISCUSSÃO 


\section{DISCUSSÃO}

O penfigoide bolhoso é uma doença vesicobolhosa rara que apresenta sintomatologia importante e é muitas vezes difícil de ser diagnosticada corretamente e em tempo hábil, sem prejudicar a qualidade de vida dos pacientes acometidos. Sua fisiopatologia, assim como em diversas doenças autoimunes, ainda é muito estudada por causa da complexidade do seu mecanismo de ação.

Atualmente o tratamento do PB é realizado por imunossupressão em longo prazo, e tem como objetivo a regressão da fase aguda da doença e a estabilização de suas manifestações clínicas mais importantes, que é alcançada na maioria dos casos. Entretanto, uma parcela dos casos não tem uma resposta terapêutica tão eficaz, e é necessário administrar doses altas de corticosteroides em associação com outros imunossupressores para o controle efetivo da moléstia.

É imperativo, sem dúvida, descobrir os mecanismos fisiopatológicos envolvidos para poder avançar tanto no diagnóstico, quanto no uso de agentes terapêuticos mais eficazes e com menores efeitos colaterais e promover, portanto, mais benefícios aos pacientes com PB e outras doenças autoimunes.

No presente estudo, foi coletada uma amostra de sangue de 17 casos de pacientes diagnosticados com penfigoide bolhoso e comparada com um grupo controle de 297 doadores de órgãos. Com relação ao gênero, pouco mais da metade dos casos com penfigoide bolhoso era do gênero feminino $(52,9 \%)$ e aproximadamente $62 \%$ do 
grupo controle eram do gênero masculino. No entanto, não se encontrou associação estatisticamente significativa entre o gênero e os grupos $(p=0,232)$.

Os casos eram predominantemente constituídos por indivíduos brancos $(58,8 \%)$, seguidos de pardos $(35,3 \%)$ e negros $(5,9 \%)$, e sua classificação foi obtida de forma subjetiva, ou seja, o próprio paciente determinava sua cor. No grupo controle não havia informação sobre a cor de pele dos doadores de órgãos para viabilizar essa correlação. De qualquer modo, os estudos atuais mostram as correlações entre populações como um todo, não subdividindo com relação a cor da pele.

Com relação à idade, observaram-se diferenças estatisticamente significativas entre os pacientes com PB (média de 63,7 anos) e controles (média 43,03 anos) com $p$ $<0,001$. Provavelmente essa diferença está no fato do PB acometer indivíduos com idades mais avançadas, ao passo que no grupo controle existia uma parcela maior de jovens em sua composição, pois os doadores tendem a ser indivíduos jovens e saudáveis com morte encefálica. Entretanto, essa diferença de idade não interfere no resultado final, uma vez que a incidência de PB é muito rara (de $2,6^{[92]}$ a $42,8^{[5]}$ por milhão de hab.) e a chance de encontrar um resultado falso-negativo no grupo controle se torna muito baixa.

Segundo Marazza et al. (2009) ${ }^{[93]}$ a frequência de PB aumenta consideravelmente após os 70 anos e a incidência máxima após os 90 anos. Porém, Bourdon-Lanoy et al. (2005) ${ }^{[94]}$ relataram que o PB entre os jovens costuma ser mais severo e mais ativo que nas pessoas mais idosas.

Além do fator idade, o PB já foi associado a diversos fatores de "gatilho" e os mais comuns são os diuréticos, analgésicos, antibióticos e os anti-hipertensivos ${ }^{[95,56]}$. 
No presente estudo, a maioria dos pacientes não teve associação a nenhum fator externo (Gráfico 2), apenas $1(5,9 \%)$ relatou uso de amoxicilina antes de surgir o quadro clínico de PB e $1(5,9 \%)$ associou a um período de muito estresse antes de aparecerem os sintomas.

O Ambulatório de Estomatologia do HC-FMUSP é referência nacional para o tratamento de doenças vesicobolhosas, mormente as de difícil controle do quadro clínico, o que resulta em seguimento de pacientes de todo o território nacional. Deste modo, embora a extensão geográfica do Brasil possibilite variações entre as composições alélicas entre as regiões de origem, a representatividade geográfica (Gráfico 1) do presente estudo foi relativamente abrangente. Embora a maior parte dos pacientes fosse proveniente do Sudeste $(64,7 \%)$, o grupo também era composto por pacientes do Nordeste $(23,6 \%)$, Sul (5.9\%) e Norte $(5,9 \%)$.

A miscigenação da população brasileira, uma das mais heterogêneas do mundo, apresenta uma vantagem para a realização de estudos que envolvam a genotipagem. Mediante a estratificação populacional, genes anteriormente tidos como ligados a uma determinada doença tendem a ser diluídos e como consequência, a chance de resultados falso-positivos é menor.

Nesta pesquisa, foram feitas múltiplas comparações e para ajustar o valor $p$ foi utilizada a correção de Bonferroni ${ }^{[91]}$ para evitar que fosse encontrada, ao acaso, uma associação não existente de erro tipo 1 . 


\subsection{Associação HLA e a população brasileira}

Foi observada uma associação significativa entre PB e o complexo principal de histocompatibilidade classe I (HLA C) e classe II (HLA-DQB1 e HLA-DQA1). Pacientes com penfigoide bolhoso apresentaram prevalências dos alelos HLA C*17, DQB1*03:01, DQA1*01:03 e DQA1*05:05 expressivamente maior que no grupo controle.

Com relação aos genes HLA classe $\mathrm{I}$, os indivíduos com HLA C*17 apresentaram chance oito vezes maior de ter penfigoide bolhoso quando comparados com pessoas que não têm esse alelo $(p<0,001)$. Apesar de estudos anteriores ${ }^{[74,75]}$ não comprovarem a associação com alelos classe I em outras populações, na brasileira foi possível evidenciar essa característica. Portanto, é a primeira vez que se demonstrou a correlação de um HLA classe I com o penfigoide bolhoso.

O HLA classe I foi identificado em diversos estudos em associações de casos e controles, tais como em lúpus eritematoso sistêmico ${ }^{[96]}$ psoríase $^{[97]}$ e vitiligo ${ }^{[98]}$; entretanto, na maioria das doenças autoimunes, especialmente as vesicobolhosas como o pênfigo e o penfigoide, tem sido atribuído um papel maior nos antígenos de classe II, que são encontrados com mais frequência nas diferentes populações. Prova disso, é um estudo feito com a população japonesa realizado por Okazaki et al. (2000) ${ }^{[75]}$, que envolve antígenos classe II, e que mostrou haver suscetibilidade ao PB em relação aos haplótipos HLA-DRB1*04/DQA1*03:01/DQB1*03:02 (39,1\% vs. 11,7\%; $p<$ 0,001) e DRB1*11:01/DQA1*05:05/DQB1*03:02 (8,7\% vs. 0\%; $p<0,0001)$ e os alelos DQB1*03:02 (43,5\% vs. 17,2\%; $p<0,002)$ e DRB1*11:01 (17,4\% vs. $3,2 \%$; 
$p<0,001)$. De modo similar, a presente pesquisa mostra a presença do alelo DQA1*05:05 que aumentou perto de quatro vezes $(p=0,0004)$ o risco de manifestação do PB. Entretanto, com relação aos outros genes classe II, relatados no estudo de Okazaki et al. (2000) ${ }^{[75]}$, não houve diferença estatisticamente significante.

O alelo DQA1*01:03 mostra um risco relativo de aproximadamente 3,6 vezes ( $p=0,003$ ) maior de desenvolver PB em indivíduos portadores da doença (Tabela 7). Essa nova associação ainda não tinha sido descrita na literatura, comprovando, dessa forma, a existência de diferentes alelos na gênese do penfigoide bolhoso, conforme a população estudada.

Com relação ao alelo DQB1*03:01, o estudo de Delgado et al. (1996) ${ }^{[74]}$ mostrou associação significativa na população caucasiana $(35,7 \%$ vs. $16,05 \% ; p=$ 0,005) em todas as variantes clínicas do penfigoide (forma bolhosa, ocular cicatricial e oral). De modo similar, no presente estudo, este alelo apresentou aumento de cerca de 3,8 vezes em relação ao grupo controle $(38,2 \%$ vs. $14,1 \%, p=0,000372)$, e, além disso, um papel importante na gênese do penfigoide.

Do mesmo modo como na população caucasiana, um outro estudo realizado por Esmaili et al. (2013) ${ }^{[77]}$ na população iraniana, evidenciou associação significativa com o alelo HLA-DQB1*03:01 (36\% vs. $23,6 \%, p=0,02)$, assim como os alelos HLA-DQA1*05:01 (45\% vs. 33\%, $p=0,03)$ e HLA-DQB1*04:01 (4\% vs. 1,6\%, $p=$ 0,04), em relação ao grupo controle. No entanto, no presente estudo não foi encontrado nenhum caso de portadores de PB com os alelos HLA-DQA1*05:01 e HLADQB1*04:01. Entre a população brasileira e iraniana existe em comum apenas o alelo HLA-DQB1*03:01. 
Em um estudo com a população chinesa ${ }^{[76]}$, foi evidenciado fator de proteção em indivíduos que apresentaram os alelos DRB1*08/DQB1*06 (4,08\% vs. 15,19\% e $1,54 \%$ vs. $13,82 \%$, respectivamente; $p<0,05)$. Todavia, no estudo aqui desenvolvido para a população brasileira, não foi encontrada significância estatística para os alelos DRB1*08 (2,9\% vs. $6,7 \% ; p=0,398)$ e DQB1*06 $(26,5 \%$ vs. $22,1 \% ; p=0,548)$ para o fator de proteção na população brasileira.

O presente estudo evidenciou, portanto, a descoberta de novos alelos associados ao PB, além de mostrar alelos em comum com outras populações mundiais. É mais uma contribuição para mapear e aprofundar o conhecimento da fisiopatologia envolvida em portadores de penfigoide bolhoso e delinear novas pesquisas no futuro. 
7 CONCLUSÃO 


\section{CONCLUSÃO}

Os resultados deste estudo levam a concluir que:

- A tipificação do HLA, em portadores de penfigoide bolhoso e doadores de órgãos (controles) na população brasileira, mostra que os alelos HLA C*17, DQB1*03:01, DQA1*01:03 e DQA1*05:05 estão associados à manifestação da doença, com risco relativo de 8,31 (2,46-28,16), 3,76 (1,81-7,79), 3,57 $(1,53-8,33)$ e $4,02(1,87-8,64)$, respectivamente.

- A associação entre o alelo DQB1*03:01 e o penfigoide bolhoso está descrito na literatura e presente em outras populações, comprovando, ainda mais, seu papel na fisiopatologia dessa doença autoimune.

- Pela primeira vez na literatura, um antígeno Classe I (HLA C*17) é associado ao penfigoide bolhoso. Existe, portanto, um risco elevado de que portadores desse alelo na população brasileira apresentem a doença. 
ANEXOS 


\section{ANEXO A \\ PROTOCOLO DE TIPAGEM PARA O LABORATÓRIO DE IMUNOLOGIA DO InCor}

\section{Protocolo de tipagem de HLA}

Laboratório de Imunologia - HLA

InCor, Fundação Zerbini Hospital das Clínicas da FMUSP

Protocolo de Coleta de Sangue: pesquisa de penfigoide bolhoso

Solicitante: Dr. Azis A Chagury

Coleta: 1 frasco de sangue com EDTA (tubo de hemograma)

Objetivo: Extração de DNA

Tipificação dos antígenos de Histocompatibilidade de classe I e II.

Sangue de:

Nome:

RGHC:

Data de nascimento: de. de.

Raça:

Data da coleta: 


\section{ANEXO B}

\section{TIPIFICAÇÃO HLA PELO MÉTODO PCR-SSO}

MAPA DE ENSAIO - TIPAGEM HLA CL_ASSE 1 e CI.ASSE II

HLA 1 e HLA 2

PCR-SSO (Reaçĩo em Cadkia da Polimerase - Sequència Especifica de Oligonucleotideos)
DATAt
01.12 .2015
PLACA Ot
Analista: Camila Cerqueira

\begin{tabular}{|c|c|c|c|c|}
\hline InCor Samplet 51470-2 & \multicolumn{2}{|c|}{ AMOSTRA TRANSPORTADA } & \multicolumn{2}{|c|}{ REPRODUTIBILIDADE } \\
\hline \multicolumn{5}{|l|}{$\begin{array}{r}\text { Locus A } \\
\end{array}$} \\
\hline \multicolumn{5}{|l|}{ Locus B } \\
\hline \multicolumn{5}{|l|}{ Locus DR } \\
\hline \multirow{2}{*}{\multicolumn{5}{|c|}{ Locus DQ }} \\
\hline & & & & \\
\hline \multicolumn{5}{|c|}{ REACุĀO DE PCR } \\
\hline \multicolumn{5}{|c|}{ Cálculo do Master Mix Locus A } \\
\hline \multirow[b]{2}{*}{ Reagente } & \multirow[b]{2}{*}{ Lote } & \multirow[b]{2}{*}{ Validade } & \multicolumn{2}{|c|}{ Volume em ul } \\
\hline & & & $\times 1$ & $\frac{\text { Nedempite }}{0}$ \\
\hline D-Mix & 149 & $30 / 09 / 2016$ & 6,9 & 0 \\
\hline Primer Loeven A & 011 & $31 / 03 / 2016$ & 2 & 0 \\
\hline T*q DNATian/Gen(SU/ju) & N2505 & $30 / 05 / 2016$ & 0,1 & 0 \\
\hline & ir $9 \mu \mathrm{d}$ & $0,2+1,0 \mu \mathrm{d} d \mathrm{c}$ DN & & \\
\hline
\end{tabular}

Cálculo do Master Mix Locus B

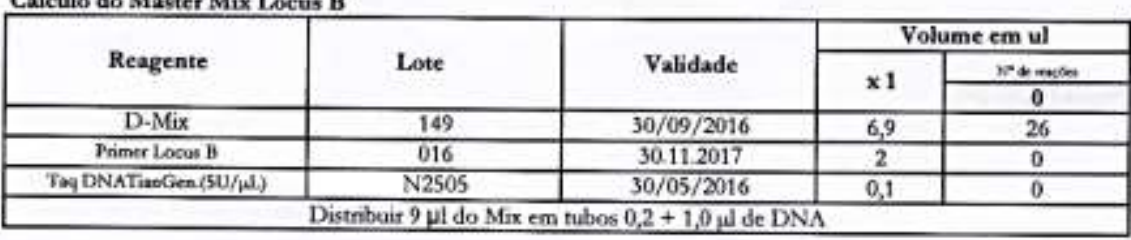

Calculo do Master Mix Locus DR

\begin{tabular}{|c|c|c|c|c|}
\hline \multirow{3}{*}{ Reagente } & \multirow{3}{*}{ Lote } & \multirow{3}{*}{ Validade } & \multicolumn{2}{|c|}{ Volume $\mathrm{cm}$ ul } \\
\hline & & & \multirow{2}{*}{$\mathbf{x 1}$} & Notserset \\
\hline & & & & 0 \\
\hline D-Mix & 149 & $30 / 09 / 2016$ & 6,9 & 0 \\
\hline Primer DR & 14 & 30.10 .2017 & 2 & 0 \\
\hline Taq DNATianGen,(SU/Mls & N2S05 & $30 / 05 / 2016$ & 0,1 & 0 \\
\hline & ar 9 uldo & $0,2+1,0 \mathrm{fdc}$ & & \\
\hline
\end{tabular}

Cálculo do Master Mix Locus DRB1 HI RESOLUTION

\begin{tabular}{|c|c|c|c|c|}
\hline \multirow{3}{*}{ Reagente } & \multirow{3}{*}{ Lote } & \multirow{3}{*}{ Validade } & \multicolumn{2}{|c|}{ Volume em ul } \\
\hline & & & $\times 1$ & NeAman \\
\hline & & & & 0 \\
\hline D-Mnx & 149 & $30 / 09 / 2016$ & 6,9 & 0,00 \\
\hline Famer DRHD & 004 & $30 / 07 / 2017$ & 2 & 0 \\
\hline Taq DNATianGen $(S U / \mu L)$ & $\mathrm{N} 2505$ & $30 / 05 / 2016$ & 0,1 & 0 \\
\hline
\end{tabular}

Cálculo do Master Mix Locus C E DQ

\begin{tabular}{|c|c|c|c|c|}
\hline \multirow{3}{*}{ Reagente } & \multirow{3}{*}{ Lote } & \multirow{3}{*}{ Validade } & \multicolumn{2}{|c|}{ Volume em ul } \\
\hline & & & \multirow{2}{*}{$\mathrm{x} 1$} & \multirow{2}{*}{$\frac{\text { Bromotes }}{0}$} \\
\hline & & & & \\
\hline D-Mix & 149 & $30 / 09 / 2016$ & 6,9 & 0,00 \\
\hline Primer $C$ e $D Q$ & $12 / 09$ & $10.2016 / 092016$ & 2 & 0 \\
\hline 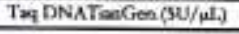 & $\mathrm{N} 2505$ & $30 / 05 / 2016$ & 0,1 & 0 \\
\hline \multicolumn{5}{|c|}{ Destribuir 9 fli do Mfrx cm tubos $0,2+1,0 \mathrm{w}$ de DNA } \\
\hline & & & & \\
\hline & & & & \\
\hline
\end{tabular}




\begin{tabular}{|c|c|c|c|}
\hline \multicolumn{4}{|c|}{ AMPLIFICAÇĀO } \\
\hline Data: & 01.12 .2015 & Termociclador - HLA - VERITI & $\begin{array}{l}\text { Prog: Hold: } 96^{\circ} \mathrm{C} \text { por } 3 \mathrm{~min} \\
5 \text { ciclos: } 96^{\circ} \mathrm{C} \text { por } 20 \mathrm{~s} \\
60^{\circ} \mathrm{C} \text { por } 20 \mathrm{~s} \\
72^{\circ} \mathrm{C} \text { por } 20 \mathrm{~s} \\
30 \text { ciclos: } 96^{\circ} \mathrm{C} \text { por } 10 \mathrm{~s} \\
60^{\circ} \mathrm{C} \text { por } 15 \mathrm{~s} \\
72^{\circ} \mathrm{C} \text { por } 20 \mathrm{~s} \\
\text { Hold: } 72^{\circ} \mathrm{C} \text { por } 10 \mathrm{~min} \\
\text { Hold: } 4^{\circ} \mathrm{C} \text { infinito }\end{array}$ \\
\hline
\end{tabular}

\begin{tabular}{|c|c|c|c|c|c|}
\hline \multicolumn{5}{|c|}{ DENATURACุÃO } & \\
\hline Reagente & Lote & Validade & Volume $\mathbf{~ x x}$ & \multicolumn{2}{|c|}{ Volume total } \\
\hline Tampào de Denaturaçào & 053 & 30.07 .2016 & 1,3 & \multicolumn{2}{|c|}{0,0} \\
\hline Tampào de Neutralização & 072 & 30.08 .2016 & 2,5 & \multicolumn{2}{|c|}{0,0} \\
\hline \multicolumn{6}{|c|}{ 2,5ul de DNA amplificado $\mathrm{p} /$ placa PCR } \\
\hline \multicolumn{6}{|c|}{$-1,3$ ul de tampào de denaturação - agitat e incubar a TA $10 \mathrm{~min}$} \\
\hline \multicolumn{6}{|c|}{$-2,5$ ul de tampão neutralização - agitar - amarelo claro } \\
\hline \multicolumn{6}{|c|}{ - banho de gelo por 5 minutos } \\
\hline \multicolumn{6}{|c|}{ HIBRIDIZACAO } \\
\hline \multirow{2}{*}{ Reagente } & \multirow{3}{*}{\multicolumn{2}{|c|}{ Lote }} & \multirow{3}{*}{ Validade } & \multirow{2}{*}{\multicolumn{2}{|c|}{$\begin{array}{l}\text { Volume } \mathrm{cm} \text { ul } \\
\text { Volume } \mathrm{em} \text { ul }\end{array}$}} \\
\hline & & & & & \\
\hline \multirow{2}{*}{ Beads Locus A } & & & & $\times 1$ & Nedentes \\
\hline & \multicolumn{2}{|c|}{014} & $31 / 09 / 2016$ & $\times 1$ & 0 \\
\hline Beads Locais B & \multicolumn{2}{|c|}{018} & 30.11 .2017 & 2 & 0 \\
\hline Beads Locus DR & \multicolumn{2}{|c|}{018} & 30.10 .2017 & 17 & 0 \\
\hline \multirow{2}{*}{$\frac{\text { Beads Locus DQ }}{\text { Tampio de Fithralixaciòo }}$} & \multirow{2}{*}{\multicolumn{2}{|c|}{$\frac{009}{064}$}} & \multirow{2}{*}{$\frac{30 / 09 / 2016}{3007,2016}$} & \multirow{2}{*}{$\mathbf{x} 1$} & Nomations \\
\hline & & & & & 0 \\
\hline & & & & 2 & 0 \\
\hline & & & & 17 & 0 \\
\hline \multicolumn{6}{|c|}{ Preparar o mix de hibridizacio de cada locus em tubos de $1,7 \mathrm{~mL}$ distintos - vortexar, } \\
\hline \multirow{2}{*}{\multicolumn{6}{|c|}{$\begin{array}{l}\text { Distribair } 18 \mathrm{LL} \text { do Mix nnos poccos correspondentes de cada locus - vortexar - incubar a } 60^{\circ} \text { por } 15 \text { min; } \\
\text { Rapidamente } 40 \text { ul do tampảo de lavagem - centrifugar } 5 \text { min }(1300 \text { g) - Flicar - Acrescentar } 40 \mathrm{ul} \text { tampào }\end{array}$}} \\
\hline & & & & & \\
\hline & lavage & & - Flicar $(2 \mathrm{x})$ & & \\
\hline
\end{tabular}

\begin{tabular}{|c|c|c|c|c|}
\hline \multicolumn{5}{|c|}{ MARCAÇAO } \\
\hline \multirow{3}{*}{ Reagente } & \multirow{3}{*}{ Lote } & \multirow{3}{*}{ Validade } & \multicolumn{2}{|c|}{ Volume em ul } \\
\hline & & & \multirow{2}{*}{$\mathbf{x} 1$} & wtireston \\
\hline & & & & 96 \\
\hline SAPE & 158 & 31.12 .2015 & 0,25 & 24,00 \\
\hline Tampào SAPE & 071 & 30.07 .2016 & 24,75 & 2376,00 \\
\hline \multicolumn{5}{|c|}{ Preparat o mix conforme o numero de testes, independente dos locus } \\
\hline \multicolumn{5}{|c|}{ Distribuir $25 \mu \mathrm{L}$ do mix de marcaçāo cm cada poço - agitar $20 \mathrm{seg}$ - incubat $60^{\circ} 5 \mathrm{~min}$} \\
\hline \multicolumn{5}{|c|}{ Rapidamente adicionar 40 ul tampäo de lavagem - centrifugar e flicar - actescentar $60 \mathrm{ul}$ - } \\
\hline \multicolumn{5}{|c|}{ Transferir $\mathrm{p} /$ placa de EI ISA fundo $\mathrm{em} U$. } \\
\hline \multicolumn{5}{|c|}{ Levar para Aquisiçāo no Luminex. } \\
\hline
\end{tabular}




\section{REFERÊNCIAS}




\section{REFERÊNCIAS $^{1}$}

1. Walsh SR, Hogg D, Mydlarski PR. Bullous pemphigoid: from bench to bedside. Drugs. 2005;65(7):905-26.

2. Stanley JR. Bullous pemphigoid. In: Freedberg IM, E.A., Wolff K, et al., eds. Fitzpatrick's Dermatology in general medicine. 5th ed. New York: McGraw-Hill, Health Professions Division, 1999:666-79.

3. Lo Schiavo A, Ruocco E, Brancaccio G, Caccavale S, Ruocco V, Wolf R. Bullous pemphigoid: etiology, pathogenesis, and inducing factors: facts and controversies. Clin Dermatol. 2013;31(4):391-9.

4. Bernard P, Vaillant L, Labeille B, Bedane C, Arbeille B, Denoeux JP, Lorette G, Bonnetblanc JM, Prost C. Incidence and distribution of subepidermal autoimmune bullous skin diseases in three French regions. Bullous Diseases French Study Group. Arch Dermatol. 1995;131(1):48-52.

5. Langan SM, Smeeth L, Hubbard R, Fleming KM, Smith CJ, West J. Bullous pemphigoid and pemphigus vulgaris--incidence and mortality in the UK: population based cohort study. BMJ. 2008;337:a180.

6. Bertram F, Brocker EB, Zillikens D, Schmidt E. Prospective analysis of the incidence of autoimmune bullous disorders in Lower Franconia, Germany. J Dtsch Dermatol Ges. 2009;7(5):434-40.

7. Gudi VS, White MI, Cruickshank N, Herriot R, Edwards SL, Nimmo F, Ormerod AD. Annual incidence and mortality of bullous pemphigoid in the Grampian region of north-east Scotland. Br J Dermatol. 2005;153:424-7.

8. Joly P, Baricault S, Sparsa A, Bernard P, Bédane C, Duvert-Lehembre S, Courville P, Bravard P, Rémond B, Doffoel-Hantz V, Bénichou J. Incidence and mortality of bullous pemphigoid in France. J Invest Dermatol. 2012;132(8):19982004.

\footnotetext{
${ }^{1}$ Esta tese está de acordo com as seguintes normas, em vigor no momento desta publicação: Referências: adaptado de International Committee of Medical Journals Editors (Vancouver) Universidade de São Paulo. Faculdade de Medicina. Serviço de Biblioteca e Documentação. Guia de apresentação de dissertações, teses e monografias. Elaborado por Anneliese Carneiro da Cunha, Maria Julia de A. L. Freddi, Maria Fazanelli Crestana, Marinalva de Souza Aragão, Suely Campos Cardoso, Valéria Vilhena. 3a ed. São Paulo: Serviço de Biblioteca e Documentação; 2011. Abreviaturas dos títulos dos periódicos de acordo com List of Journals Indexed in Index Medicus.
} 
9. Stanley JR, Hawley-Nelson P, Yuspa SH, Shevach EM, Katz SI. Characterization of bullous pemphigoid antigen: a unique basement membrane protein of stratified squamous epithelia. Cell. 1981;24(3):897-903.

10. McMillan JR, Akiyama M, Shimizu H. Epidermal basement membrane zone components: ultrastructural distribution and molecular interactions. J Dermatol Sci. 2003;31(3):169-77.

11. Nishie W. Update on the pathogenesis of bullous pemphigoid: an autoantibodymediated blistering disease targeting collagen XVII. J Dermatol Sci. 2014;73(3):179-86.

12. Sami N, Bhol KC, Beutner EH, Plunkett RW, Leiferman KM, Foster CS, Ahmed AR. Simultaneous presence of mucous membrane pemphigoid and pemphigus vulgaris: molecular characterization of both autoantibodies. Clin Immunol. 2001;100(2):219-27.

13. Sami N, Ahmed AR. Dual diagnosis of Pemphigus and pemphigoid. Retrospective review of thirty cases in the literature. Dermatol. 2001;202(4):293-301.

14. Schmidt E, Zillikens D. Modern diagnosis of autoimmune blistering skin diseases. Autoimmun Rev. 2010;10(2):84-9.

15. Labib RS, Anhalt GJ, Patel HP, Mutasim DF, Diaz LA. Molecular heterogeneity of the bullous pemphigoid antigens as detected by immunoblotting. J Immunol, 1986;136(4):1231-5.

16. Kasperkiewicz M, Zillikens D. The pathophysiology of bullous pemphigoid. Clin Rev Allergy Immunol. 2007;33(1-2):67-77.

17. Budinger L, Borradori L, Yee C, Eming R, Ferencik S, Grosse-Wilde H, Merk $\mathrm{HF}$, Yancey K, Hertl M. Identification and characterization of autoreactive T cell responses to bullous pemphigoid antigen 2 in patients and healthy controls. J Clin Invest. 1998;102(12):2082-9.

18. Romagnani S. Human TH1 and TH2 subsets: regulation of differentiation and role in protection and immunopathology. Int Arch Allergy Immunol. 1992;98(4):279-85.

19. Bernard P, Aucouturier P, Denis F, Bonnetblanc JM. Immunoblot analysis of IgG subclasses of circulating antibodies in bullous pemphigoid. Clin Immunol Immunopathol. 1990;54(3):484-94.

20. Klein J, Sato A. Advances in Immunology: The HLA System (First of Two Parts). N Engl J Med. 2000;343(10):702-9. 
21. Schaller J, Feleke W, Haustein UF, Baldauf C, Kunze G. HLA in bullous pemphigoid. The probable role of HLA-B7 as a marker for poor responders to immunosuppressive therapy. Int J Dermatol. 1991;30(1):36-8.

22. Venning VA, Taylor CJ, Ting A, Wojnarowska F. HLA type in bullous pemphigoid, cicatricial pemphigoid and linear IgA disease. Clin Exp Dermatol. 1989;14(4):283-5.

23. Venning VA, Dean D, Wojnarowska F. Absence of expression of class II major histocompatibility complex determinants on keratinocytes in bullous pemphigoid. Br J Dermatol. 1992;126(5):463-7.

24. Bizzozero G. Saggio di studio sulla cosidetta endogenesi del pus. Gazz Med Ital. Lombardia. 1872:33-8.

25. Schaffer J. Vorlesungen über Histologie und Histogenese. Leipzig, 1920.

26. Odland GF. The fine structure of the interrelationship of cells in the human epidermis. J Biophys Biochem Cytol. 1958;4(5):529-38.

27. Koch PJ, Walsh MJ, Schmelz M, Goldschmidt MD, Zimbelmann R, Franke WW. Identification of desmoglein, a constitutive desmosomal glycoprotein, as a member of the cadherin family of cell adhesion molecules. Eur J Cell Biol. 1990;53(1):1-12.

28. Hieda Y, Nishizawa Y, Uematsu J, Owaribe K. Identification of a new hemidesmosomal protein, HD1: a major, high molecular mass component of isolated hemidesmosomes. J Cell Biol. 1992;116(6):1497-506.

29. Owaribe K, Kartenbeck J, Stumpp S, Magin TM, Krieg T, Diaz LA, Franke WW. The hemidesmosomal plaque. I. Characterization of a major constituent protein as a differentiation marker for certain forms of epithelia. Differentiation. 1990;45(3):207-20.

30. Fontao L, Stutzmann J, Gendry P, Launay JF. Regulation of the type II hemidesmosomal plaque assembly in intestinal epithelial cells. Exp Cell Res. 1999;250(2):298-312.

31. Litjens SHM, Sonnenberg A. Hemidesmosomes. In: Encyclopedic Reference of Genomics and Proteomics in Molecular Medicine. 2006, Springer Berlin Heidelberg: Berlin, Heidelberg. pp. 754-758.

32. Uzun S. Pemphigus in the Mediterranean region of Turkey: a study of 148 cases. Int J Dermatol. 2006;45(5):523-8. 
33. Baican A, Pemphigus vulgaris is the most common autoimmune bullous disease in Northwestern Romania. Int J Dermatol. 2010. 49(7):768-74.

34. Serwin AB. Epidemiological and clinical analysis of pemphigoid patients in northeastern Poland in 2000-2005. Med Sci Monit. 2007;13(8):CR360-4.

35. Cozzani E. Bullous pemphigoid in Liguria: a 2-year survey. J Eur Acad Dermatol Venereol. 2001;15(4):317-9.

36. Nanda A, Dvorak R, Al-Saeed K, Al-Sabah H, Alsaleh QA. Spectrum of autoimmune bullous diseases in Kuwait. Int J Dermatol. 2004. 43(12):876-81.

37. Wong SN, Chua SH. Spectrum of subepidermal immunobullous disorders seen at the National Skin Centre, Singapore: a 2-year review. Br J Dermatol. 2002. 147(3):476-80.

38. Waisbourd-Zinman O, Ben-Amitai D, Cohen AD, Feinmesser M, Mimouni D, Adir-Shani A, Zlotkin M, Zvulunov A. Bullous pemphigoid in infancy: Clinical and epidemiologic characteristics. J Am Acad Dermatol. 2008;58(1):41-8.

39. Zaraa, I, Kerkeni N, Ishak F, Zribi H, El Euch D, Mokni M, Osman AB. Spectrum of autoimmune blistering dermatoses in Tunisia: an 11-year study and a review of the literature. Int J Dermatol. 2011;50(8):939-44.

40. Di Zenzo G, Marazza G, Borradori L. Bullous pemphigoid: physiopathology, clinical features and management. Adv Dermatol. 2007;23:257-88.

41. Kneisel A, Hertl M. Autoimmune bullous skin diseases. Part 1: Clinical manifestations. J Dtsch Dermatol Ges. 2011;9(10):844-56; quiz 857.

42. Schmidt E, della Torre R, Borradori L. Clinical features and practical diagnosis of bullous pemphigoid. Dermatol Clin, 2011;29(3):427-38, viii-ix.

43. Mihalyi L, Kiss M, Dobozy A, Kemény L, Husz S. Clinical relevance of autoantibodies in patients with autoimmune bullous dermatosis. Clin Dev Immunol. 2012;2012:369546.

44. Chorzelski TP, Jablońska S. Clinical variants of pemphigoid. Int J Dermatol. 1986;25(10):669-70.

45. Korman N. Bullous pemphigoid. J Am Acad Dermatol. 1987;16(5Pt 1):907-24.

46. Urano S. Localized bullous pemphigoid of the vulva. J Dermatol. 1996;23(8):5802. 
47. Mysorekar VV, Sumathy TK, Shyam Prasad AL. Role of direct immunofluorescence in dermatological disorders. Indian Dermatol Online J. 2015;6(3):172-80.

48. Woodley DT. Immunofluorescence on salt-split skin for the diagnosis of epidermolysis bullosa acquisita. Arch Dermatol. 1990;26(2):229-31.

49. Gammon WR, Fine JD, Forbes M, Briggaman RA. Immunofluorescence on split skin for the detection and differentiation of basement membrane zone autoantibodies. J Am Acad Dermatol. 1992;27(1):79-87.

50. Di Zenzo G, Thoma-Uszyński S, Fontao L, Calabresi V, Hofmann SC, Hellmark T, Sebbag N, Pedicelli C, Sera F, Lacour JP, Wieslander J, Bruckner-Tuderman L, Borradori L, Zambruno G, Hertl M. Multicenter prospective study of the humoral autoimmune response in bullous pemphigoid. Clin Immunol. 2008;128(3):415-26.

51. Heimbach L, Li Z, Berkowitz P, Zhao M, Li N, Rubenstein DS, Diaz LA, Liu Z. The C5a receptor on mast cells is critical for the autoimmune skin-blistering disease bullous pemphigoid. J Biol Chem. 2011;286(17):15003-9.

52. Wojnarowska F, Venning VA, Burge SM. Immunobullous diseases. In: Burns T, Breathnach S, Cox N, Griffiths C, Rook's Textbook of Dermatology (Seventh Edition), 2008:60.

53. Laszlo S, Neumann S, Hertl M, Hunzelmann N. Generation of increased numbers of HLA-DR(high) IgG+ plasma cells in the peripheral blood of patients with bullous pemphigoid: NC16a-specific cells belong to the short-lived plasma blast population. J Invest Dermatol. 2010;130(12):2838-41.

54. Venning VA, Wojnarowska F. Induced bullous pemphigoid. Br J Dermatol. 1995;132(5):831-2.

55. Popadic S, Skiljevic D, Medenica L. Bullous pemphigoid induced by penicillamine in a patient with Wilson disease. Am J Clin Dermatol. 2009;10(1):36-8.

56. Mallet L, Cooper JW, Thomas J. Bullous pemphigoid associated with captopril. DICP. 1989;23(1):63.

57. Wozniak K, Kowalewski C, Hashimoto T, Ishii N, Glinska-Wielochowska M, Schwartz RA. Penicillin-induced anti-p200 pemphigoid: an unusual morphology. Acta Derm Venereol. 2006;86(5):443-6. 
58. Walmsley N, Hampton P. Bullous pemphigoid triggered by swine flu vaccination: case report and review of vaccine triggered pemphigoid. J Dermatol Case Rep. 2011;5(4):74-6.

59. Muramatsu T, Yamashina Y, Shirai T, Ohnishi T. UVB irradiation reduces the expression of pemphigoid antigens in organ-cultured normal human skin. Arch Dermatol Res. 1994;286(3-4):142-4.

60. Vermeulen C, Janier M, Panse I, Daniel F. [Localized bullous pemphigoid induced by thermal burn]. Ann Dermatol Venereol. 2000;127(8-9):720-2.

61. Balato N, Ayala F, Patruno C, Ruocco V. Bullous pemphigoid induced by a thermal burn. Int J Dermatol. 1994;33(1):55-6.

62. Nozu T, Mita H. Bullous pemphigoid and percutaneous endoscopic gastrostomy. Intern Med. 2010;49(11):971-5.

63. Isohashi F, Konishi K, Umegaki N, Tanei T, Koizumi M, Yoshioka Y. A case of bullous pemphigoid exacerbated by irradiation after breast conservative radiotherapy. Jpn J Clin Oncol. 2011;41(6):811-3.

64. Chen TJ, Lai PC, Yang LC, Kuo TT, Hong HS. Bullous pemphigoid in a renal transplant recipient: a case report and review of the literature. Am J Clin Dermatol. 2009;10(3):197-200.

65. Drago F, Nozza P, Casazza S, Brusati C, Bandelloni R, Rebora A. Human herpesviruses in bullous pemphigoid lesions. Br J Dermatol. 2005;152(2):375-6.

66. Hertl M, Eming R, Veldman C. T cell control in autoimmune bullous skin disorders. J Clin Invest. 2006;116(5):1159-66.

67. Fernandes APM, Maciel LMZ, Foss MC, Donadi EA. Como entender a associação entre o sistema HLA e as Doenças Auto-imunes endócrinas. Arq Bras Endocrinol Metab. 2003;47(5):601-611.

68. Reveille JD. The genetic basis of autoantibody production. Autoimmun Rev. 2006;5(6):389-98.

69. Ahmed AR, Cohen E, Blumenson LE, Provost TT. HLA in bullous pemphigoid. Arch Dermatol. 1977;113(8):1121.

70. Weber R, M. F, Preuhs-Filho G, Rodrigues H, Kalil J, Miziara ID. HLADRB1*04:02, DRB1*08:04 and DRB1*14 alleles associated to pemphigus vulgaris in southeastern Brazilian population. Tissue Antigens. 2011;78(2):923. 
71. Luis-Montoya P, Yamamoto-Furusho JK, Vega-Memije E, Rodríguez-Carreón A, Ruiz-Morales JA, Vargas-Alarcón G, Domínguez-Soto L, Granados J. HLA$D R B 1 * 0101$ is associated with the genetic susceptibility to develop lichen planus in the Mexican Mestizo population. Arch Dermatol Res. 2007;299(8):405-7.

72. Haase O, Alneebari R, Eldarouti MA, Abd El Hady M, Dorgham D, El-Nabarawy E, El Din Mahmoud SB, Mosaad El Sayed H, Darwish M, et al. Association with HLA-DRB1 in Egyptian and German pemphigus vulgaris patients. Tissue Antigens. 2015;85(4):283-6.

73. Weber R, Monteiro F, Preuhs-Filho G, Rodrigues H, Kalil J, Miziara ID. HLADRB1*04:02, DRB1*08:04 and DRB1*14 alleles associated to pemphigus vulgaris in southeastern Brazilian population. Tissue Antigens. 2011;78(2):92-3.

74. Delgado JC, Turbay D, Yunis EJ, Yunis JJ, Morton ED, Bhol K, Norman R, Alper CA, Good RA, Ahmed R. A common major histocompatibility complex class II allele $H L A-D Q B 1 * 0301$ is present in clinical variants of pemphigoid. Proc Natl Acad Sci U S A. 1996;93(16):8569-71.

75. Okazaki A, Miyagawa S, Yamashina Y, Kitamura W, Shirai T. Polymorphisms of HLA-DR and -DQ genes in Japanese patients with bullous pemphigoid. J Dermatol. 2000;27(3):149-56.

76. Gao XH, Winsey S, Li G, Barnardo M, Zhu XJ, Chen HD, Song F, Zhai N, Fuggle $\mathrm{S}$, Wojnarowska F. HLA-DR and DQ polymorphisms in bullous pemphigoid from northern China. Clin Exp Dermatol. 2002;27(4):319-21.

77. Esmaili N, Mortazavi H, Chams-Davatchi C, Daneshpazhooh M, Damavandi MR, Aryanian Z, Amirzargar AA. Association between HLA-DQB1*03:01 and Bullous pemphigoid in Iranian patients. Iran J Immunol. 2013;10(1):1-9.

78. Yunis JJ, Mobini N, Yunis EJ, Alper CA, Deulofeut R, Rodriguez A, Foster CS, Marcus-Bagley D, Good RA, Ahmed AR. Common major histocompatibility complex class II markers in clinical variants of cicatricial pemphigoid. Proc Natl Acad Sci U S A. 1994;91(16):7747-51.

79. Setterfield J, Theron J, Vaughan RW, Welsh KI, Mallon E, Wojnarowska F, Challacombe SJ, Black MM. Mucous membrane pemphigoid: HLA-DQB1*0301 is associated with all clinical sites of involvement and may be linked to antibasement membrane IgG production. Br J Dermatol. 2001;145(3):406-14. 
80. Carrozzo M, Fasano ME, Broccoletti R, Carbone M, Cozzani E, Rendine S, Roggero S, Parodi A, Gandolfo S. HLA-DQB1 alleles in Italian patients with mucous membrane pemphigoid predominantly affecting the oral cavity. $\mathrm{Br} \mathrm{J}$ Dermatol. 2001;145(5):805-8.

81. Drouet M, Delpuget-Bertin N, Vaillant L, Chauchaix S, Boulanger MD, Bonnetblanc JM, Bernard P. HLA-DRB1 and HLA-DQB1 genes in susceptibility and resistance to cicatricial pemphigoid in French Caucasians. Eur J Dermatol. 1998;8(5):330-3.

82. Attia J, Ioanidis J, Thakkinstian A, McEvoy M, Scott RJ, Minelli C, Thompson J, Infante-Rivard C, Guyatt $\mathrm{G}$. How to use an article about genetic association. A Background concepts. JAMA, 2009;301(3):304-8.

83. Suarez-Kurtz G. Pharmacogenomics and the genetic diversity of the Brazilian population. Cad Saude Publica. 2009;25(8):1650-1.

84. Moraes ME, Fernandez-Viña M, Salatiel I, Tsai S, Moraes JR, Stastny P. HLA class II DNA typing in two Brazilian populations. Tissue Antigens. 1993;41(5):238-42.

85. Alves-Silva J, da Silva Santos M, Guimarães PE, Ferreira AC, Bandelt HJ, Pena $\mathrm{SD}$, Prado VF. The ancestry of Brazilian mtDNA lineages. Am J Hum Genet. 2000;67(2):444-61.

86. Cesbron-Gautier A, Simon P, Achard L, Cury S, Follea G, Bignon JD. [Luminex technology for HLA typing by PCR-SSO and identification of HLA antibody specificities]. Ann Biol Clin (Paris). 2004;62(1):93-8.

87. Pei R, Lee JH, Shih NJ, Chen M, Terasaki PI. Single human leukocyte antigen flow cytometry beads for accurate identification of human leukocyte antigen antibody specificities. Transplantation. 2003;75(1):43-9.

88. NMDP. HLA Resources: Allele Code List in Alphabetical Order. 2015.

89. Plackett RL. Karl Pearson and the Chi-Squared Test. International Statistical Review. Rev Int Statist. 1983;51(1):59-72.

90. Lee E, Lendas KA, Chow S, Pirani Y, Gordon D, Dionisio R, Nguyen D, Spizuoco A, Fotino M, Zhang Y, Sinha AA. Disease Relevant HLA Class II Alleles Isolated by Genotypic, Haplotypic, and Sequence Analysis in North American Caucasians With Pemphigus Vulgaris. Hum Immunol. 2006;67:125-39. 
91. Bonferroni CE. Teoria statistica delle classi e calcolo delle probabilità, in Pubblicazioni del R. Istituto Superiore di Scienze Economiche e Commerciali di Firenze. 1936. p. 3-62.

92. Nanda A, Al-Saeed K, Dvorak R, Al-Muzairai I, Al-Sabah H, Al-Arbash M, Alsaleh QA. Clinicopathological features and HLA tissue typing in pemphigoid gestationis patients in Kuwait. Clin Exp Dermatol. 2003;28(3):301-6.

93. Marazza G, Pham HC, Schärer L, Pedrazzetti PP, Hunziker T, Trüeb RM, Hohl $\mathrm{D}$, Itin $\mathrm{P}$, Lautenschlager S, Naldi L, Borradori L. Incidence of bullous pemphigoid and pemphigus in Switzerland: a 2-year prospective study. Brit $\mathrm{J}$ Dermatol. 2009;161(4):861-8.

94. Bourdon-Lanoy E, Roujeau JC, Joly P, Guillaume JC, Bernard P, Prost C, Tancrède-Bohin E, Delaporte E, Picard-Dahan C, Albes B, Bedane C, Doutre MS, et al. [Bullous pemphigoid in young patients: a retrospective study of 74 cases]. Ann Dermatol Venereol. 2005;132(2):115-22.

95. Lee JJ, Downham TF 2nd. Furosemide-induced bullous pemphigoid: case report and review of literature. J Drugs Dermatol. 2006;5(6):562-4.

96. Millard TP, McGregor JM. Molecular genetics of cutaneous lupus erythematosus. Clin Exp Dermatol. 2001;26(2):184-91.

97. Gonzaga HF, Torres EA, Alchorne MM, Gerbase-Delima M. Both psoriasis and benign migratory glossitis are associated with HLA-Cw6. $\mathrm{Br} \mathrm{J}$ Dermatol. 1996;135(3):368-70.

98. Orecchia G, Perfetti L, Malagoli P, Borghini F, Kipervarg Y. Vitiligo is associated with a significant increase in HLA-A30,Cw6 and DQw3 and a decrease in C4AQO in northern Italian patients. Dermatol. 1992;185(2):123-7. 
APÊNDICES 


\title{
APÊNDICE 1
}

\section{TERMO DE APROVAÇÃO DO COMITÊ DE ÉTICA PARA ANÁLISE DE PROJETOS DE PESQUISA}

\author{
Hospital das Clínicas da FMUSP
}

Comissão de Ética para Análise de Projetos de Pesquisa - CAPPesq

\section{PROJETO DE PESQUISA}

Titulo: ESTUDO DA ASSOCIAÇ̄̄OO ENTRE ANTIGENOS DE HLA - DR E DQ - EM PENFIGÓIDE BOLHOSO EM PACIENTES BRASHELROS

Pesquisador Responsável: Prof Dr lvan Dieb Miziara Versāo: 1

Pesquisador Executante: Azis Arruda Chagury CAAE: 17049313.1.0000.0068

Finalidade Acadêmica Doutorado

Orientador: Prof Dr lvan Dieb Miziara

Instituição: HCFMUSP

Departamento: OFTALMOLOGIA E OTORRINOLARINGOLOGLA

\section{PARECER CONSUBSTANCIADO DO CEP}

Registro on-line: 10827

Número do Parecer: 294.201

Data da Relatoria: 05/06/13

Apresentação do Projeto: 0 projeto é apresentado de modo claro, com boa redaçăo. A revisăo da literatura embasa os objetivos do proje to de pesquisa.

Objetivo da Pesquisa; Identificar alelos do sistema HLA loci DR e DQ de pacientes brasileiros portadores de penfigóide bolhoso, identificando aqueles associados à doença através da comparaçăo da prevalência desses alelos com as de um grupo controle.

Avaliaçăo dos Riscos e Beneficios: 0 risco para os pacientes é minimo, pois o procedimento a ser realizado é a colheita de amostra de sangue $(5$ a $10 \mathrm{ml})$ através de punção venosa. Näo haverá beneficios diretos para os pacientes.

Comentários e Consideraçôes sobre a Pesquisa: Trata-se de projeto de pesquisa bem formulado. A casuistica é composta por pacientes com diagnóstico bem estabelecido de penfigoide bolhoso e que estäo em seguimento na Divisäo de Clinica onde será realizado o projeto de pesquisa. Os dados do sistema HLA dos pacientes será comparado aqueles de banco de dados de individuos normais brasileiros. 0 orçamento apresentado é adequado.

Rua Dr. Ovidio Pires de Campos, 225 - Prédio da Administraç̄o - $5^{e}$ andar CEP 05403-010 - Sāo Paulo - SP

5511 2661-7585 - 5511 2661-6442 ramais: $16,17,18$ | marcia carvalho she. fm usp br 
Hospital das Clínicas da FMUSP

Comissão de Ética para Análise de Projetos de Pesquisa - CAPPesq

Consideraçōes sobre os Termos de apresentaçăo obrigatória: O TCIF é redigido de modo adequado, Tem texto claro objetivo.

Recomendaçŏes: Nada a recomendar.

Conclusöes ou Pendências e Lista de Inadequaçōes:

Situaçăo do Parecer: Aprovado,

Necessita Apreciaçăo da CONEP: Năo.

Consideraçōes Finais a critério do CEP: Em conformidade com o itern $\mid X .2$ da Resaluçä́o CNS nt 196/96 - cabe ao pesquisador a) desenvolver o projeto conforme dedineado; b) elaborar e apresentar relatórios patciais e final; cłapresentar dados solicitados pelo CEP, a qualquer momento, d) inanter em arquivo sob sua zuarda, por 5 anos $d$ a pesquisa, contendo fichas intividuais e todos as demais documentos recomendados pelo CEP, e) encaminhar os tesultados parat publicaçdo, com os devidos credtitos am pesquisadores associados a ao pessoal tècricn participante do projeto; f) justificar perante ao CEP interrupç̄̄o do projeto ou a nắo publicaçåo đos resultados.

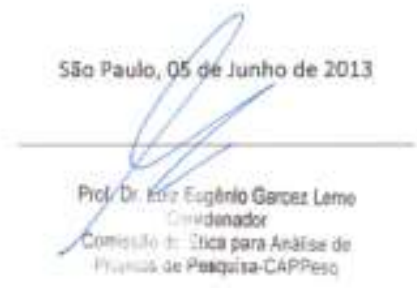

Rua Dr. Ovidio Pires de Campos, 225 - Prédio da Administraçäa - 58 andar CEP 05403-010-Sło Paulo - SP.

$55112661-7585-55112661-6442$ ramais: $16,17,18$ | marciacarvatho@hc. fm.usp.be 


\section{APÊNDICE 2 \\ TERMODE CONSENTIMENTO LIVRE E ESCLARECIDO \\ HOSPITAL DAS CLÍNICAS DA FACULDADE DE MEDICINA \\ DA UNIVERSIDADE DE SÃO PAULO-HCFMUSP \\ TERMO DE CONSENTIMENTO LIVRE E ESCLARECIDO}

I - DADOS DE IDENTIFICAÇÃO DO SUJEITO DA PESQUISA OU RESPONSÁVEL LEGAL

1. NOME DO PACIENTE:

DOCUMENTO DE IDENTIDADE №: SEXO: $M \square F$

DATA DE NASCIMENTO: № APTO:

ENDEREÇO: CIDADE:

BAIRRO: TELEFONE: DDD (.......)

2. RESPONSÁVEL LEGAL:

NATUREZA (grau de parentesco, tutor, curador, etc.):

DOCUMENTO DE IDENTIDADE: SEXO: $\mathrm{M} \square \mathrm{F} \square$ DATA DE NASCIMENTO: ....................

ENDEREÇO: № APTO:

BAIRRO: CIDADE:

CEP: TELEFONE: DDD (.......)

\section{II - DADOS SOBRE A PESQUISA}

1. TÍTULO DO PROTOCOLO DE PESQUISA. "Estudo da associação entre antígenos de HLA - DR e DQ - em pacientes brasileiros com penfigoide bolhoso" PESQUISADOR: Prof. Dr. Ivan Dieb Miziara CARGO/FUNÇÃO: Livre Docente, Médico Chefe do Ambulatório de Estomatologia INSCRIÇÃO CONSELHO REGIONAL: № 45484 UNIDADE DO HCFMUSP: Disciplina de Otorrinolaringologia

2. AVALIAÇÃO DO RISCO DA PESQUISA:

$$
\begin{array}{ll}
\text { RISCO MÍNIMO X } & \text { RISCO MÉDIO } \\
\text { RISCO BAIXO } \square & \text { RISCO MAIOR }
\end{array}
$$

3. DURAÇÃO DA PESQUISA: 48 meses 


\section{III - REGISTRO DAS EXPLICAÇÕES dO PESQUISADOR AO PACIENTE OU SEU REPRESENTANTE LEGAL SOBRE A PESQUISA CONSIGNANDO:}

O objetivo do presente estudo é identificar como a genética do paciente pode estar associada ao desenvolvimento da doença Penfigoide. Determinados pacientes foram escolhidos, segundo alguns critérios, para participar do estudo e, após essa escolha, os pacientes podem optar, livremente, se desejam ou não participar. Caso optem por participar do estudo, os pacientes serão submetidos à coleta de uma amostra de sangue (5-10 ml ou 2 colheres de chá) da veia do antebraço, num determinado local e horário, combinados com o pesquisador. Todo material de coleta será novo, estéril e manuseado por profissional capacitado para o trabalho.

No estudo, não há benefício direto para o participante, pois se trata de um estudo experimental que tentará descobrir a causa da doença para, futuramente, contribuir para o tratamento dessa enfermidade. Além disso, é garantida a liberdade da saída do estudo a qualquer momento, sem qualquer prejuízo à continuidade de seu tratamento na instituição.

Em qualquer etapa do estudo, você terá acesso aos profissionais responsáveis pela pesquisa para esclarecimento de eventuais dúvidas. O principal investigador é o Dr. Azis Arruda Chagury, que pode ser encontrado na Divisão de Clínica de Otorrinolaringologia no Instituto Central do Hospital das Clínicas - FMUSP Av. Dr. Enéas de Carvalho Aguiar, 255 CEP 05403-900 - São Paulo - SP - Brasil, Telefone: +55 11 2661-6288, celular 15 981188687.

Se você tiver alguma consideração ou dúvida sobre a ética da pesquisa, entre em contato com o Comitê de Ética em Pesquisa (CEP) - Rua Ovídio Pires de Campos, 225 - 5은 andar - Telefone: 2661-6442 ramais 16, 17, 18 - e-mail: cappesq@hcnet.usp.br.

Seus dados serão mantidos em sigilo - As informações obtidas serão analisadas em conjunto com outros pacientes, não sendo divulgado sua identificação. $O$ paciente será atualizado sobre os resultados parciais das pesquisas, caso seja necessário e/ou acrescente alguma melhora para o tratamento do mesmo.

Não há compensação financeira das despesas pessoais para o participante em qualquer fase do estudo, incluindo exames e consultas. Também não há compensação relacionada à sua participação.

Por fim, fica claro o compromisso do pesquisador de utilizar os dados e o material coletado somente para esta pesquisa.

\section{IV - ESCLARECIMENTOS DADOS PELO PESQUISADOR SOBRE GARANTIAS DO SUJEITO DA PESQUISA CONSIGNANDO:}

Acredito ter sido suficientemente informado a respeito das informações que li ou que foram lidas para mim, descrevendo o "Estudo da associação entre antígenos de HLA DR e DQ - em pacientes brasileiros com penfigoide."

Eu discuti com o Dr. Azis Arruda Chagury sobre a minha decisão em participar nesse estudo. Ficaram claros para mim quais são os propósitos do estudo, os procedimentos a serem realizados, seus desconfortos e riscos, as garantias de confidencialidade e de 
esclarecimentos permanentes. Ficou claro também que minha participação é isenta de despesas e que tenho garantia do acesso a tratamento hospitalar quando necessário.

Concordo voluntariamente em participar deste estudo e poderei retirar o meu consentimento a qualquer momento, antes ou durante o mesmo, sem penalidades ou prejuízo ou perda de qualquer benefício que eu possa ter adquirido, ou no meu atendimento neste Serviço.

\section{V - INFORMAÇÕES DE NOMES, ENDEREÇOS E TELEFONES DOS RESPONSÁVEIS PELO ACOMPANHAMENTO DA PESQUISA, PARA CONTATO EM CASO DE INTERCORRÊNCIAS CLÍNICAS E REAÇÕES ADVERSAS.}

Dr. Azis Arruda Chagury - Divisão de Otorrinolaringologia

Av. Dr. Enéas de Carvalho Aguiar, 255 Tel. (11) 2661-6288 Celular: (15) 9 8118-8687

\section{VI - OBSERVAÇÕES COMPLEMENTARES}

\section{VII - CONSENTIMENTO PÓS ESCLARECIDO}

Declaro que, após convenientemente esclarecido pelo pesquisador e ter entendido o que me foi explicado, consinto em participar do presente Protocolo de Pesquisa

São Paulo, de de $20 \ldots \ldots . . .$.

Assinatura do sujeito da pesquisa* ou representante legal
Dr. Azis Arruda Chagury pesquisador

* Para casos de pacientes menores de 18 anos, analfabetos, semianalfabetos ou portadores de deficiência auditiva ou visual.

(Somente para o responsável do projeto)

Declaro que obtive de forma apropriada e voluntária o Consentimento Livre e Esclarecido deste paciente ou representante legal para a participação neste estudo.

$\overline{\text { Assinatura do responsável pelo estudo }}$

São Paulo, de de 20 